Quaestio facti. Revista Internacional sobre Razonamiento Probatorio Quaestio facti. International Journal on Evidential Legal Reasoning Sección: Ensayos N. 2 | 2021 pp. 53-85 Madrid, 2021

DOI: 10.33115/udg_bib/qf.i2.22463 Marcial Pons Ediciones Jurídicas y Sociales (C) Jeffry José Mora Sánchez ISSN: 2604-6202

Recibido: 22/06/2010 | Aceptado: 28/08/2020 | Publicado: 29/01/2021 Editado bajo licencia Reconocimiento 4.0 Internacional de Creative Commons

\title{
PREDICTIBILIDAD CONDUCTUAL Y PROCESO PENAL: ALGUNOS APUNTES SOBRE EL FUNDAMENTO EPISTÉMICO DE LOS HECHOS FUTUROS EN LAS MEDIDAS CAUTELARES
}

\author{
Jeffry José Mora Sánchez \\ Juez Penal, Poder Judicial de Costa Rica \\ jmorasa@poder-judicial.go.cr \\ jjmsabogado@gmail.com
}

RESUMEN: La determinación de hechos futuros en un proceso penal implica un juicio predictivo conductual que, como cualquier otra decisión, debe basarse en elementos epistémicos sólidos y generarse a partir de un razonamiento inferencial válido. Desde la perspectiva señalada, la inferencia probatoria que el juzgador realice, para avalar la disposición de una medida cautelar, deberá incorporar una garantía, constituida por máximas de experiencia, presunciones o definiciones. El presente texto se ocupa de evaluar, partiendo del diseño procesal penal costarricense, cómo debe presentarse ese razonamiento inferencial, así como los aportes que la psicología cognitiva, los instrumentos actuariales y la inteligencia artificial pueden brindar, con el objetivo de construir resoluciones judiciales racionales e intersubjetivamente controlables, en un rubro tan relevante como el de las medidas cautelares y la prisión preventiva.

PALABRAS CLAVE: Hechos futuros; inferencia probatoria; psicología cognitiva; instrumento actuarial; garantía.

\section{BEHAVIORAL PREDICTABILITY AND CRIMINAL PROCEEDINGS: SOME NOTES ON THE EPISTEMIC FOUNDATION OF FUTURE EVENTS IN PRECAUTIONARY MEASURES}


ABSTRACT: The determination of future events in a criminal process implies a predictive behavioral judgment that, like any other decision, must be based on solid epistemic elements and generated from valid inferential reasoning. From the indicated perspective, the evidentiary inference that the judge makes, to endorse the provision of a precautionary measure, must incorporate a guarantee, consisting of maxims of experience, presumptions or definitions. The present text deals with evaluating, based on the Costa Rican criminal procedural design, how this inferential reasoning should be presented, as well as the contributions that cognitive psychology, actuarial instruments and artificial intelligence can provide, with the objective of building rational and intersubjectively controllable judicial resolutions, in an area as relevant as that of precautionary measures and preventive detention.

KEYWORDS: future facts; evidentiary inference; cognitive psychology; actuarial instrument; warrant.

SUMARIO: 1. INTRODUCCIÓN.-2. JUSTIFICACIÓN DE LA PREMISA FÁCTICA DE LAS MEDIDAS CAUTELARES: 2.1. Factores procesales positivos: 2.1.1. Incompletitud del elenco probatorio. 2.1.2. Devaluación de la garantía del derecho a la prueba. 2.2. Factores de resiliencia interna del decisor. 2.3. Factores estructurales de la pretensión.-3. LA INFERENCIA PROBATORIA EN LOS HECHOS FUTUROS: 3.1. ¿Jueces gurús, bouche de la loi o decisores racionales?: 3.1.1. Presunciones iuris o definiciones. 3.1.2. Máximas de experiencia.—4. EL BACKING DEL WARRANT EN LOS HECHOS FUTUROS: 4.1. La psicología cognitiva y la estadística. 4.2. La inteligencia artificial. 4.3. ¿Cuál es el rendimiento de la estadística?- - CONCLUSIONES.-6. BIBLIOGRAFÍA.

RECOMMENDED CITATION: MORA SÁNCHEZ, J. J., 2020: «Predictibilidad conductual y proceso penal: algunos apuntes sobre el fundamento epistémico de los hechos futuros en las medidas cautelares», in Quaestio facti, 2: 53-85. Madrid: Marcial Pons Ediciones Jurídicas y Sociales. DOI: http://dx.doi.org/10.33115/udg_bib/qf.i2.22463

"Man can believe the impossible, but man can never believe the improbable» Intentions, Oscar WiLde.

"A medida que se moderen las penas, que se supriman la sordidez y el hambre de las cárceles, que la compasión y la humanidad traspongan las puertas con cerrojos e inspiren a los inexorables y empedernidos ministros de justicia, las leyes podrán contentarse con indicios cada vez más débiles para capturan De los delitos y de las penas, Cesare BeCCARIA.

"[E]l derecho penal debe esforzarse por aniquilar no solo a quien efectivamente haya perturbado la paz en casos concretos (...) toda futura perturbación de la paz y todas las predisposiciones que se correspondan con ella deberán combatirse con la totalidad de las armas idóneas para la defensa» Derecho penal de voluntad, Roland FreIsLER. 


\section{INTRODUCCIÓN}

En el año 2002 el director estadounidense Steven Spielberg llevó a la pantalla grande la distopía futurista Minority Report, basada en el cuento de Philip Kindred Dick. La película narra el ocaso de una unidad policial (PreCrime) que se vale de tres hermanos psíquicos (precogs) cuya habilidad innata les permite predecir homicidios; sin embargo, la promisoria institución represiva se desploma cuando se evidencia la falibilidad de las precogniciones. El escenario presentado en el filme representa uno de los implícitos anhelos de cualquier modelo de justicia penal, al punto que, aunque no se perciba con especial facilidad, algunas instituciones jurídicas funcionan desde larga data bajo la lógica de la predictibilidad conductual.

Los esfuerzos que encumbraron desde el positivismo criminológico Enrico Ferri, Cesare Lombroso y Rafael Garófalo, arguyendo la predisposición anatómica de ciertas personas para incurrir en conductas ilícitas, ha sido afablemente receptada por algunos Estados totalitarios como andamiaje de políticas públicas de criminalización de enemigos ${ }^{1}$, pero también perviven en la forma en que opera el aparato represivo en algunos países de semblanza liberal y democrática, pero con altísima selectividad criminal, dirigida a ciertas clases de individuos ${ }^{2}$. En la actualidad, el desarrollo de las neurociencias, especialmente los estudios relacionados con la vinculación del lóbulo frontal del cerebro y la toma de decisiones (Silva, Mercurio, y López 2008: 76-112) plantea enormes tensiones desde el punto de vista ético, al resultar plausible que en algún momento el sueño de Lombroso y sus acólitos tenga aún mayor acogi$\mathrm{da}$, esta vez refrendado por la autoridad de la ciencia.

Pero al margen de idealismos y posturas extremas superadas, al menos formalmente, el proceso penal ha dado buen recaudo a ciertos actos que requieren un ejercicio prospectivo y no retrospectivo, dentro de los cuales, por su nivel de impacto en la esfera de derechos fundamentales de las personas, la determinación de medidas cautelares de carácter personal ${ }^{3}$, sin duda alguna, es la más prominente, en especial cuando de prisión preventiva se trata ${ }^{4}$. La decisión judicial que se pronuncia sobre la

1 Con una mera intención ejemplificativa puede verse el panfleto político elaborado por Roland Freisler, el llamado "soldado político de Hitler», de donde se ha extraído la cita colocada en el epígrafe de esta monografía (FreIsLer 2017: 117-118).

2 Quizá el caso estadounidense sea el más paradigmático, por su autoconcepción como la meca de la libertad y la democracia. Refiriéndose a la anormal proporción de gente afrodescendiente en prisión en este país, puede verse: CHRIsTIE 2004: 171-175.

3 En adelante, cuando se haga referencia a medidas cautelares deberá entenderse que se trata de cualesquiera medidas de carácter personal y no real, incluyendo por supuesto la prisión preventiva.

4 Aunque en el presente trabajo se ha preferido el abordaje general de las medidas cautelares, es evidente que los mayores problemas prácticos se dan con relación a la prisión preventiva. No obstante, debe hacerse hincapié en que los modelos argumentativos y la construcción de la inferencia probatoria será, en esencia, idéntica para uno u otro caso, pues lo que marca la diferencia en la aplicación de las diversas tipologías de medidas precautorias es la ponderación en cuanto a la entidad del riesgo y el estándar probatorio determinado para cada una de estas. 
determinación de medidas cautelares contra un individuo requiere poco menos que la clarividencia del juzgador, dado que este necesariamente debe pronunciarse sobre dos aspectos medulares': la probabilidad de que contra el investigado se emita una sentencia condenatoria ${ }^{6}$ y la probabilidad de que la libertad del imputado entrañe la afectación del proceso, sea por fuga o por alteración o desaparición de pruebas ${ }^{7}$.

Dado que técnicamente es imposible probar algo que no ha ocurrido, a no ser que se pueda vincular causalmente de forma necesaria con un hecho que ya ha acontecido (FerRer Beltrán 2019: 205), si se excluye la efectiva práctica de la nigromancia por parte del juzgador, resulta evidente la dificultad que este tendrá para apoyar su decisión. Pero entonces, ¿qué tipo de razonamiento efectúan los jueces cuando disponen la prisión preventiva u otra medida cautelar contra un individuo?; ¡es posible dotar de un sustrato epistémico robusto tales decisiones?

Siendo que, como bien señala González LAGier, dentro de la estructura de cualquier inferencia probatoria el elemento esencial es la garantía (2013: 40), constituida por máximas de experiencia, presunciones o definiciones, resulta imprescindible explorar qué tipo de producto cognitivo puede alimentar una determinación tan relevante como la acá analizada. En esta empresa, el conocimiento derivado de la psicología cognitiva y los progresos relacionados con la inteligencia artificial podrían significar un avance, pero también, tal y como en el filme de SPIELBERG, un enorme retroceso en la búsqueda de decisiones judiciales más racionales en estos rubros. A estas y otras disquisiciones se destinarán las siguientes páginas.

\section{JUSTIFICACIÓN DE LA PREMISA FÁCTICA DE LAS MEDIDAS CAUTELARES}

Aunque la premisa normativa de las medidas precautorias, conforme con la concepción cautelar ${ }^{8}$, es susceptible de fundadas críticas $^{9}$, es la premisa fáctica la que

5 El análisis parte del diseño procesal penal costarricense, el cual es, en líneas generales, similar al de la mayoría de los países latinoamericanos, al tener como base el Código Procesal Penal modelo para Iberoamérica de 1988. Sobre esta uniformidad relativa, particularmente en la regulación de las medidas cautelares, puede verse: Dei Vecchi 2015; Llobet 2018: 590-591; MAier 1996.

${ }^{6}$ Este rubro implica que se corrobore la probabilidad de que se haya dado un hecho ilícito y la participación del investigado en este. Se ha querido presentar este aspecto material de la premisa normativa de esta forma a fin de evidenciar que se trata de una proposición diversa a la relativa a la decisión final, lo que permitiría establecer estándares de prueba idénticos en ambos casos, sin que signifique una «sentencia temprana». Sobre este punto se volverá en los apartados siguientes.

7 Se asume stricto sensu la concepción cautelar, con el único fin de facilitar el análisis de los hechos futuros en las medidas cautelares, pero sin inobservar que la mayoría de los países latinoamericanos han incorporado en sus codificaciones causales de orden punitivo, contrariando abiertamente los lineamientos que ha erigido la Corte Interamericana de Derechos Humanos. Sobre el tema puede consultarse: Mora 2019: 220-222; Mora 2015: 83-95.

8 Sobre la concepción cautelar vid.: DeI VeCCHI 2015a; Mora 2019: 216-218.

Nota 9 en página siguiente 
es la premisa fáctica la que comporta mayor dificultad operativa para los administradores de justicia penal. Las complicaciones pueden devenir de al menos tres tipos de variables: los factores procesales positivizados en las legislaciones; los factores de resiliencia interna del juzgador; y los factores estructurales de la pretensión.

\subsection{Factores procesales positivos}

Independientemente del diseño procesal del sistema penal que se trate, por la naturaleza de las medidas cautelares, su requerimiento se da en etapas tempranas de la investigación, lo que implica, habida cuenta de la necesidad de restringir potenciales detenciones arbitrarias, la fijación de plazos cortos para definir la situación jurídica del imputado, a partir del momento en que finalmente es aprehendido ${ }^{10}$.

Si a lo dicho se suma el exceso de carga laboral ${ }^{11}$ y las presiones políticas para la macdonalización ${ }^{12}$ de la justicia penal, se comprenderá sin dificultad que no nos encontramos ante un escenario ideal para la evaluación de restricciones en derechos fundamentales de personas que no han sido condenadas y que, en principio, se ven resguardadas por el principio de presunción de inocencia.

\subsubsection{Incompletitud del elenco probatorio}

Uno de los parámetros de justificación epistémica que la doctrina especializada ha desarrollado es precisamente la completitud (comprehensiveness) ${ }^{13}$ o inclusividad (Ferrer Beltrán 2019: 273), que se refiere a la cantidad de pruebas relevantes dis-

9 Esencialmente, en cuanto al fumus commissi delicti, se cuestiona su compatibilidad con la presunción de inocencia como regla de trato (sobre este particular vid. FERnández López 2004: 218-222; FERRER BeLtrán 2019: 195-199), mientras que en lo relativo al periculum libertatis, las principales críticas derivan del establecimiento de causales que persiguen fines punitivos y no precautorios (vid.: Mora 2019: 216-224).

10 El Código Procesal Penal costarricense (en adelante CPP) establece, en su art. 238: «(...) Si la persona se encontrare detenida, la solicitud de audiencia deberá pedirse dentro de las veinticuatro horas, contadas desde que el encausado se puso a la orden del juez; la audiencia deberá celebrarse dentro de las cuarenta y ocho horas y la resolución deberá ser dictada dentro de ese plazo».

11 Aunque de acuerdo con el III Informe sobre el Estado de la Justicia, pese al incremento en la cantidad de jueces, entre los años 2016 y 2018 se muestra una disminución de los asuntos resueltos de forma definitiva en materia penal, con un total de 163.630 casos, lo que representa una disminución del -0,1 por 100, entre un año y otro (2020: 170).

12 Las limitaciones de mi memoria me han impedido recordar dónde leí por primera vez esta frase, no obstante, la referencia corresponde a Manuel Miranda Estrampes, quien se refirió a la «macdonalización y guantamización de los sistemas latinoamericanos por influencia norteamericana», durante las lecciones que impartió en el seno del Máster en Razonamiento Probatorio de la Universidad de Girona, en el año 2018.

13 "(...) comprehensiveness is one determinant of quality of evidence that thorough inquiry requires not only sifting and weighing the available evidence, but also, when necessary, seeking out additional evidence 
ponibles para alcanzar una decisión. La premura con que se desarrolla la evaluación de medidas cautelares impide que se cuente, en la mayoría de los casos, con la totalidad de las pruebas relevantes para la determinación de la verdad, dado que, aunque la detención del imputado se haya dado luego de una exhaustiva investigación - piénsese, por ejemplo, en casos de delincuencia económica- y el Ministerio Público lograra acumular una enorme cantidad de evidencia, en este supuesto sería la defensa la que se encontraría en aprietos para procurar prueba de descargo, con las limitaciones que conlleva el tiempo para hacerlo, el estado psicológico del imputado — posiblemente en shock - y la restricción momentánea de su libertad ambulatoria.

La imposibilidad material de que la defensa procure prueba puede repercutir negativamente en los intereses del investigado, ya que hipótesis alternativas en favor de la libertad del imputado podrían no ser respaldadas epistémicamente. Pero en muchas otras ocasiones la situación es aún más grave, pues en supuestos de sucesos de violencia intempestiva, en donde no se ha podido realizar investigación previa, tanto la prueba de cargo como de descargo se ve sensiblemente constreñida.

Supongamos un caso de homicidio, en donde solamente existe un testigo que afirma haber visto al investigado corriendo desde el lugar de los hechos, con manchas rojas en su camisa, encontrándose pendiente toda la prueba pericial que usualmente se dispone en este tipo de asuntos, incluyendo análisis balísticos, de huellas dactilares, de elementos pilosos u otro material orgánico, etc. Resulta claro que los estudios científicos podrían dotar de un alto grado de confirmación a la hipótesis del ente acusador, o bien, descartarla, también con un importante grado de solidez; sin embargo, el juez deberá determinar la condición en que el investigado afrontará el resto del proceso -en libertad, en prisión, con un mecanismo electrónico de seguimiento u otra medida- prescindiendo de esa evidencia.

\subsubsection{Devaluación de la garantía del derecho a la prueba}

Si bien puede discutirse que el vocablo prueba se utilice en contextos distintos a la etapa de juicio, «desde el punto de vista epistemológico no hay distinción alguna (...) [t]odo elemento de juicio relevante para tomar una decisión sobre la ocurrencia de un hecho es una prueba» ${ }^{14}$ (Ferrer Beltrán 2019: 194), con independencia de si se les denomina elementos de convicción, evidencia, indicios o cualquier otra nomenclatura. Empero, en las audiencias de medidas cautelares las garantías correlativas al derecho de defensa y vinculadas con la actividad probatoria se ven a menudo disminuidas, especialmente porque no se presenta una práctica de la prueba siquiera

(which reminds me to remind you of the two meanings of "partial": "biased" and "incomplete")" (НAacK 2014: 31).

14 Cfr. Valenzuela 2018: 843, quien afirma que "pareciera que la prueba en el sistema procesal es aquella que tiene lugar en la audiencia de juicio oral pues el legislador usa ese vocablo (prueba o medios de prueba) cuando se diseñan las condiciones para la decisión del juicio». 
semejante a la que se genera en la etapa de juicio, donde el principio de contradicción resulta determinante.

Aunque el CPP costarricense prevé la posibilidad de recibir (y practicar) prueba para la aplicación de las medidas cautelares, incluso de forma oficiosa por parte del juez ${ }^{15}$, esta no podría ser tomada en cuenta en juicio, salvo que se utilice el procedimiento de prueba anticipada (Llobet 2017: 403). En la práctica judicial es el Ministerio Público el que suele recibir la denuncia y entrevistar testigos, sin presencia del encartado o su defensor ${ }^{16}$, de manera que lo que se lleva a la audiencia para sostener la gestión fiscal son los documentos en donde constan las manifestaciones de los involucrados.

El problema de la inclusión de manifestaciones de individuos mediante documentos puede visualizarse al menos desde dos frentes: en primer lugar, por la imposibilidad de ejercer el derecho de defensa y el principio de contradicción con respecto a la fuente de prueba, ya que no puede cuestionarse directamente la información vertida por el denunciante o el testigo ${ }^{17}$.

En segundo lugar, por la existencia de heurísticos ${ }^{18}$ que acarrean sesgos de información como el denominado sesgo del entrevistador (CERDA LorCa y VALDIVIA CABRERA 2020), según el cual quien recepta la información interpreta la misma y la modula a la hora de reflejarla por escrito, con el potencial riesgo de variar el mensaje en aspectos relevantes, siendo esto notorio, por ejemplo, cuando el lenguaje utilizado no se corresponde con las características socio-educativas del entrevistado, entreviéndose la jerga judicial.

15 Art. 242: «Prueba para la aplicación de medidas cautelares. El fiscal o, en su caso el Tribunal, podrán recibir prueba, de oficio o a solicitud de parte, con el fin de sustentar la aplicación, revisión, sustitución, modificación o cancelación de una medida cautelar. Dicha prueba se agregará a un legajo especial cuando no sea posible incorporarla al debate. El tribunal valorará estos elementos de prueba conforme a las reglas generales establecidas en este Código y exclusivamente para fundar la decisión sobre la medida cautelar. Si el tribunal lo estima necesario, antes de pronunciarse, podrá convocar a una audiencia oral para oír a las partes o para recibir directamente la prueba. De dicha audiencia se levantará un acta».

${ }^{16}$ Lo que ha sido avalado por la Sala Constitucional de Costa Rica, mediante el voto 13255-11 (citado por: LLOBEt 2017: 403).

17 Este punto es fundamental si se repara en que, en muchas ocasiones, por ejemplo, en agresiones sexuales o violencia de género, solamente se contará en la audiencia con la denuncia por escrito de la presunta víctima.

${ }_{18}$ De interés puede mencionarse el heurístico de la representatividad, que sugiere que las personas toman sus decisiones a partir de situaciones que les resultan familiares (Nieva Fenoll 2010: 121), lo que se ajusta a la labor que realizan los secretarios o los fiscales que toman denuncias en multiplicidad de causas penales y que puede arrastrarlos a acomodar la información que reciben, aun de manera inconsciente. 


\subsection{Factores de resiliencia interna del decisor}

Algunos estudios empíricos han mostrado cómo una multiplicidad de factores externos puede incidir de manera determinante en el juzgador, al momento de resolver una solicitud de imposición de medidas cautelares, relacionados con la participación y cobertura de medios de comunicación masiva, el criterio de la sociedad civil y los órganos políticos e incluso con la instrucción de causas disciplinarias en su contra ${ }^{19}$.

Cómo inciden estos factores en el juez dependerá de un amplísimo rango de vectores, que van desde su madurez, nivel de conocimiento, situación familiar, estabilidad laboral, etc. El llamado miedo social al falso negativo (Muñoz VicENTE y López-Ossorio 2016: 134), concepto tomado de la psicología cognitiva y que denota el sesgo que llevaría al juez a disponer una medida cautelar ante la incertidumbre de que, de no hacerlo, pueda el imputado incurrir en una conducta indeseable, con lo que se incrementa, por razones obvias, la posibilidad de falsos positivos, también es un elemento que merece atención y que podría ser reflejo de la incidencia de los factores externos descritos, pero su génesis podría también encontrarse en la alineación ideológica del juez, por ejemplo, si ha resultado ser un seguidor de posturas autoritarias o expansionistas del derecho penal.

De cualquier forma, siendo inasequible lo que ocurre en la mente del decisor, los esfuerzos para morigerar posibles influencias externas o el influjo de corrientes ideológicas que choquen con un modelo de estado liberal, es preciso fortalecer el principio de independencia judicial, en donde ya se cuenta con un plexo normativo internacional amplio ${ }^{20}$, así como el control de la racionalidad de las resoluciones, empresa esta última que, como se verá, no resulta simple, habida cuenta de las características que poseen los enunciados a probar para aplicar una medida cautelar.

19 Vid., entre otros: Chinchilla Calderón y García Aguilar 2003; Mora 2019; Vega Monge 2015. En el II Informe sobre el Estado de la Justicia, se presentaron entrevistas realizadas a 763 funcionarios judiciales (funcionarios de la judicatura, la defensa pública y la policía judicial), en donde se consultó sobre su percepción en cuanto a los criterios para la disposición de prisión preventiva, se señalaron aspectos como los prejuicios contra determinados grupos, el criterio de asociaciones de víctimas, la posibilidad de enfrentar procesos disciplinarios, la opinión pública y los medios de comunicación, entre otros (2017: 285-86). El informe puede consultarse en: www.estadonacion.or.cr

20 La importancia de establecer un abordaje integral de la independencia judicial se imbuye en los "Principios de Bangalore sobre la Conducta Judicial» (aprobados por el Consejo Económico y Social de las Naciones Unidas en su resolución E/CN.4/2003/65/Anexo, en la Haya, en noviembre de 2002 y adoptados el 10 de enero de 2003), en donde se subrayó en su preámbulo que, dada la relevancia de la independencia judicial, los diferentes actores sociales (Poder Ejecutivo, Poder Legislativo, abogados y público en general) deben comprender y apoyar el ejercicio de la judicatura. Sobre el tema vid. además: Mora 2015: 38-48. 


\subsection{Factores estructurales de la pretensión}

Conforme con el esquema elaborado por Stephen Toulmin, la pretensión (GonZÁlez LAGIer 2013: 40) o afirmación (Toulmin 2007: 132-39) constituye el punto de partida de cualquier argumentación. La particularidad de las medidas cautelares es que en estas esa pretensión, tanto en lo atinente al fumus commissi delicti como en lo relativo al periculum libertatis, es un enunciado formulado de manera prospectiva, es decir, se trata de una hipótesis sobre hechos futuros (Valenzuela 2018: 841-42).

Como ya se ha adelantado, se asume en este trabajo la postura concebida por Ferrua, según la cual el fumus commissi delicti es una hipótesis diversa a la premisa fáctica relativa a la decisión final, en tanto, mientras que en el primer caso debe probarse la probabilidad de que el proceso culmine con una sentencia condenatoria contra el imputado, es decir, un pronóstico sobre el resultado del proceso en sí mis$\mathrm{mo}^{21}$, en el segundo, la prueba será dirigida a la acreditación concreta del hecho y la participación del encartado.

Como puede verse, la diferencia radica en que la premisa fáctica del fumus commissi delicti («es probable que el proceso culmine con una sentencia condenatoria contra Fausto») incorpora una hipótesis probabilística que trasciende los aspectos probatorios relacionados con la justificación de la hipótesis de la sentencia. Al considerar que se trata de proposiciones diversas, se sortea el problema de mantener estándares probatorios idénticos y provocar una «sentencia temprana» (FerRUa 2018: 120) con el dictado de medidas cautelares altamente invasivas como la prisión preventiva $^{22}$. En este sentido, Nieva ha estimado como un «error común» que los jueces desatiendan este aspecto y se concentren exclusivamente en el periculum libertatis, con lo que ignoran «el presupuesto principal que se está comentando: la constancia de un hecho con caracteres de delito y su prácticamente indudable atribución a una persona» (2018: 72), es decir, se trata de un umbral probatorio asimilable al necesario para condenar.

La asunción de la concepción cautelar trae consigo, necesariamente, que a las medidas cautelares se le atribuyan las características de instrumentalidad, excepcionalidad, legalidad y jurisdiccionalidad (Dei Vecchi 2015b: 35), siendo a partir de esta última propiedad que se torna imprescindible la justificación, en el caso concre-

21 Agradezco a Diego Dei Vecchi por sugerir este punto.

22 Ferrua considera que la determinación de diversos estándares de prueba para distintas fases del proceso penal constituye «una perspectiva inaceptable porque, al disminuir el estándar de la prueba más allá de toda duda razonable, el concepto mismo de probar se omite y se entra en el ámbito de las ilusiones y sospechas» (2018:120; traducción libre). Cfr. Ferrer Beltrán 2019: 208, para quien, en el caso de la prisión preventiva, «la exigencia probatoria deberá ser superior que la prevista para el inicio de actuaciones penales pero inferior al estándar de prueba establecido para la condena». 
to, de la premisa fáctica de la medida ${ }^{23}$, lo que requiere un ejercicio calificatorio y el despliegue del razonamiento inferencial probatorio ${ }^{24}$.

Según lo señalado, mientras que la justificación del fumus commissi delicti coincide parcialmente con la justificación de la decisión final (existencia del hecho y participación del imputado), pero con la relevante diferencia apuntada, relativa a la incorporación de una hipótesis probabilística sobre el resultado del proceso, la gran dificultad que se presenta para justificar adecuadamente el periculum libertatis surge de las características del supuesto de hecho previsto en la premisa normativa, pues se trata de un hecho futuro ${ }^{25}$, en donde se evalúa una peligrosidad de segundo orden, dado que es preciso realizar una prognosis sobre la producción de un evento relevante y, además, de la producción de un resultado concreto a partir de ese evento (DEI VECCHI 2015a: 3).

En otras palabras, se trata de una especie de peligro de peligro, una hipótesis probabilística doble, en donde el pronóstico no solamente se da con respecto a la creación de cierta secuela, sino también en cuanto al hecho base (DEI VECCHI 2015a: 3). Partiendo de los peligros procesales regulados en el CPP ${ }^{26}$, sean el peligro de fuga ${ }^{27}$ y el riesgo de obstaculización ${ }^{28}$, la justificación de la premisa fáctica tendría que consi-

23 De acuerdo con DeI VeCCHI, para tener por probada una premisa fáctica se debe: probar un enunciado acerca de un hecho (acá se imbuyen las categorías de enunciado probatorio e inferencia probatoria); determinar si ese enunciado es una instancia particular del supuesto de hecho de la premisa normativa (incorpora las categorías enunciado calificatorio y razonamiento calificatorio) (2015b:2).

${ }^{24}$ Sobre la problemática que entraña la diferenciación entre quaestio iuris y quaestio facti, puede verse: GonZÁlez LAGIER 2013: 29-36. El autor señala: «La calificación jurídica opera ciertamente con hechos, pero es una operación interpretativa que no podría realizarse sin normas; y -lo que es más grave y menos evidente- la prueba también está teñida de normatividad» (2013: 35).

25 «La prueba de hechos futuros o los future dangerousness assessments, como se les conoce en la doctrina anglosajona, presenta una enorme trascendencia en los procesos penales, principalmente en la determinación de medidas cautelares y prisión preventiva (...) En cualquier caso, se trata de acontecimientos futuros, no susceptibles de prueba directa, que se asientan en la conjetura de su eventual existencia» (Mora 2018). También utilizando esta nomenclatura, vid. Hunter Ampuero 2015.

${ }^{26}$ Como ya se ha dicho, por no corresponder con la concepción cautelar, se prescindirá en este análisis de los riesgos de tipo punitivo.

27 Art. 240 CPP: «Peligro de fuga. Para decidir acerca del peligro de fuga se tendrán en cuenta, especialmente, las siguientes circunstancias: a) Arraigo en el país, determinado por el domicilio, residencia habitual, asiento de la familia, de sus negocios o trabajo y las facilidades para abandonar definitivamente el país o permanecer oculto. La falsedad, la falta de información o de actualización del domicilio del imputado constituirá presunción de fuga. b) La pena que podría llegarse a imponer en el caso. c) La magnitud del daño causado. d) El comportamiento del imputado durante el procedimiento o en otro proceso anterior, en la medida que indique su voluntad de someterse a la persecución penal» (el destacado es propio).

28 Art. 241 CPP: «Peligro de obstaculización. Para decidir acerca del peligro de obstaculización para averiguar la verdad se tendrá en cuenta, especialmente, la grave sospecha de que el imputado: a) Destruirá, modificará, ocultará o falsificará elementos de prueba. b) Influirá para que coimputados, testigos o peritos informen falsamente o se comporten de manera desleal o reticente, o inducirá a otros a realizar tales comportamientos. El motivo sólo podrá fundar la prisión hasta la conclusión del debate» (el destacado es propio). 
derar, por ejemplo, la probabilidad de que Fausto intente salir del país para eludir la acción de la justicia, además de la probabilidad de que Fausto en efecto salga del país y eluda la acción de la justicia.

Desde la perspectiva señalada, prohijando la postura sostenida por DeI VeCCHI, se considera que solamente es posible probar, en estricto sentido, el periculum libertatis, enlazando la noción de riesgo o peligro con la ejecución de acciones concretas (con lo que se asimila el peligro procesal al fumus commissi delicti, en cuanto al mecanismo inferencial necesario para probarlo, como una probabilidad de primer orden), pese al coste político evidente que esa asunción acarrearía ${ }^{29}$.

Lo anterior se explica en razón de que, como se verá en los capítulos siguientes, en cualquier esquema argumentativo, si las razones (conforme con la nomenclatura de Toulmin) también son prospectivas, es decir, no tienen un referente empírico, sea que estas las defina el legislador mediante el recurso de los llamados indicios tipo o sea el juez el que seleccione cuales son las razones o los datos necesarios y suficientes, se establecería un vínculo conceptual que es ajeno al razonamiento probatorio como tal (Dei VeCCHi 2015a: 8) ${ }^{30}$.

Tomando en consideración lo expuesto hasta este punto, en el capítulo siguiente se trazarán algunas líneas con relación al diseño de la inferencia probatoria en hechos prospectivos, con especial énfasis en los elementos de la garantía y el respaldo.

\section{LA INFERENCIA PROBATORIA EN LOS HECHOS FUTUROS}

El modelo simple de análisis de los argumentos, de acuerdo con la teoría de Stephen Toulmin, identifica cuatro elementos en cualquier género de razonamiento: pretensión (claimt), razones (grounds), garantía (warrant) y respaldo (backing) (Atienza 2005: 84-87; GonzÁlez Lagier 2013: 40-44; Toulmin 2007b). Conforme con este modelo, traspuesto al razonamiento judicial en materia de medidas cautelares, la pretensión sería la hipótesis inicial, por ejemplo, el enunciado «Fausto en libertad se fugará e impedirá la continuación del proceso»; si la pretensión se cuestiona, el proponente tendrá que ofrecer las razones, que son los hechos que constituyen el supuesto de hecho de la norma aplicable al caso en cuestión (v.gr. «Fausto no posee

29 «El único modo de sortear este obstáculo, sin renegar de una genuina finalidad cautelar y manteniendo una noción de peligrosidad procesal susceptible de prueba, sería ligando esta última noción a la ejecución de acciones procesalmente peligrosas concretas por parte de ciertas personas, a modo de tipos coercitivos semejantes a las figuras que determinan las acciones punibles. Es decir, resulta insoslayable el abandono de la noción de periculum libertatis como peligro de segundo orden» (DeI VeCCHI 2015a: 9). Cfr. Ferrer Beltrán 2019:205; Nieva Fenoll 2018: 79.

30 En sentido similar, FerRer Beltrán ha considerado que «es extraordinariamente difícil acreditar suficientemente la hipótesis de riesgo procesal», salvo aquellos casos en que el investigado ha intentado ya acciones tendientes a su fuga o la desaparición de pruebas incriminatorias (2019: 207). 
arraigo domiciliar en el país»); para autorizar o explicar el paso de un enunciado a otro, es decir, de las razones a la pretensión, se utiliza la garantía, que se presenta como una máxima de experiencia, una presunción o definiciones o teorías (GonzÁLEZ LAGIER 2013: 43) (v.gr. "Las personas que no tienen domicilio frecuentemente se fugan»); finalmente se presenta el respaldo, que serviría como andamiaje de la garantía (v.gr. «estudios efectuados desde la psicología cognitiva demuestran que las personas sin domicilio tienden a fugarse»).

Como puede verse, el esquema argumentativo descrito es formalmente aplicable al razonamiento judicial que se presenta al evaluar la aplicación de medidas cautelares. Sin embargo, en la práctica la garantía no suele explicitarse, con lo que la inferencia se convierte en un razonamiento entimemático o, como bien refiere Dei Vecchi, tendría que concluirse que se está ante resoluciones arbitrarias (2015a: 6), siendo una incógnita la manera en que los jueces razonan realmente ${ }^{31}$, lo que a su vez mengua la adecuada fundamentación de la resolución judicial.

Asimismo, el mayor inconveniente que se presenta al trabajar con hechos prospectivos es que, a diferencia de los hechos retrospectivos, en donde se trata de corroborar o afirmar como verdadera la ocurrencia de un hecho, en estos el enunciado a probar como tal es una hipótesis probabilística ${ }^{32}$ (DEI VeCCHI 2015a: 3), cuestión que dificulta sobremanera fundar suficientemente la garantía, máxime cuando se trate de medidas cautelares como la prisión preventiva o el monitoreo mediante dispositivos electrónicos, que requieren rebasar, al menos idealmente, un riguroso estándar de prueba, habida cuenta del enorme impacto que tienen en la esfera de derechos del imputado ${ }^{33}$.

31 La ambivalencia en cuanto a la forma en que asumen los operadores de justicia los denominados indicios tipo imbuidos en el CPP costarricense se ha reflejado en una investigación realizada mediante una entrevista semiestructurada a 43 funcionarios vinculados con la administración de justicia (16 mujeres y 27 hombres), en donde el 77 por 100 de los entrevistados señaló que tales indicadores eran presunciones iuris tantum, el 8 por 100 que eran indicios taxativos que necesariamente debían acreditarse y solamente el 15 por 100 estimó que se trataban de indicios ejemplificativos (Mora 2019: 230). Los datos resultan relevantes en tanto, dependiendo de la forma en que se entienda el indicio tipo, así corresponderá la clase de garantía, sea una máxima de experiencia, una presunción o una definición.

${ }^{32}$ Como ya se ha indicado, incluso de segundo orden, en el caso del periculum libertatis.

33 Aunque la determinación del estándar de prueba aplicable es una decisión de política criminal, lo cierto es que el juicio de ponderación de intereses en juego parece hacer recomendable que se otorgue prevalencia a la afectación concreta al individuo, cuando «el mal que se trata de evitar sea uno de producción incierta respecto del cual no puede formularse más que un pronóstico de peligro más o menos fundado, mientras que el mal que se produce (...) es un menoscabo prolongado e indefinido del derecho fundamental a la libertad real, efectivo y actual, además de irreparable, es demostrativo por sí solo de la considerable mayor gravedad del mal causado con respecto al que se trata de evitar» (Gracia Martín, citado por Martínez Garay 2014: 55). 


\section{1. ¿Jueces gurús, bouche de la loi o decisores racionales?}

Quizá el elemento más relevante en el razonamiento inferencial sea la garantía y su correspondiente respaldo, entendido este último como «el fundamento cognoscitivo en virtud del cual la inferencia puede considerarse fundada y apta para atribuir un grado considerable de fiabilidad a la respectiva conclusión» (TARUfFo 2010: 237). De acuerdo con González Lagier la garantía puede estar constituida por máximas de experiencia, presunciones o por definiciones o teorías (2013: 43), lo que está íntimamente relacionado con el diseńo procesal que se disponga para un acto determinado.

El CPP costarricense establece, con relación a las causales para la aplicación de medidas cautelares, específicamente en cuanto al riesgo de fuga, algunos indicios tipo que podrían entenderse como presunciones legales, ya que incorporan circunstancias que el decisor deberá tener «especialmente» en cuenta, a saber: arraigo en el país (domiciliar, familiar y laboral); facilidades para abandonar definitivamente el país u ocultarse; falsedad o falta de información sobre el domicilio (lo que constituye "presunción de fuga»); la posible pena por imponer; la magnitud del daño causado; el comportamiento del imputado, en cuanto refleje su voluntad de someterse a la persecución penal ${ }^{34}$.

El punto determinante es si dentro de un sistema de prueba libre, regido bajo la etérea noción de la sana crítica racional, pero que, en esencia, requiere razones epistémicas para fundar una decisión, podrían utilizarse presunciones o definiciones como enlace de la inferencia, más aún cuando en juego está uno de los bienes jurídicos de mayor valía, como lo es la libertad. Asimismo, si el enlace es una máxima de experiencia, es preciso establecer aquellas características del respaldo que permitirían dar solidez a la conclusión.

\subsubsection{Presunciones iuris o definiciones}

Si se estima que los indicios tipo, descritos en el acápite anterior, se tratan de presunciones jurídicas, estas operan como una fórmula de distribución de la carga de la prueba $^{35}$, si la presunción es refutable (presunción iuris tantum), o como una regla jurídica inderrotable, si la presunción es concluyente (presunción iuris et de iure) (Schauer 2013: 228-32). En cualquier caso, los datos constituidos por los referidos

34 Art. 240 del Código Procesal Penal. Vid. la nota al pie número 31, en cuanto a la forma en que las personas vinculadas con la administración de justicia han entendido esta regulación normativa.

35 Sobre la carga de la prueba, de forma crítica, vid. Nieva Fenoll, Ferrer Beltrán, y Giannini, 2019. 
indicadores tendrían como garantía, no un componente fáctico, sino un elemento normativo, que los excluye como genuinas pruebas ${ }^{36}$.

De esta forma, para que haya una genuina justificación probatoria de la premisa fáctica del periculum libertatis, necesariamente deben entenderse los indicadores referidos como presunciones hominis, es decir, como indicios ${ }^{37}$ o datos cuyo respaldo se constituye por consideraciones empíricas, por máximas de la experiencia (DEI VeCCHI 2015a: 6) ${ }^{38}$. En síntesis, «[l]a diferencia entre presunciones [iuris] y máximas de experiencia es que las presunciones son enunciados revestidos de autoridad» (GonZÁlez LAGier 2013: 44), que pueden verse también como «máximas de experiencia institucionalizadas y autoritativas» (GonZÁlez LAGIER 2013: 59), lo que hace recordar aquella famosa frase de MontesQuieu, plasmada en «El espíritu de las leyes», que propugnaba que el juez es la boca muda que pronuncia las palabras de la ley (Fernández Sepulveda 1985: 133).

En cuanto a las definiciones o teorías, de acuerdo con González LAGIER, estas pueden derivar de la doctrina, la jurisprudencia o inclusive de la ley, pero, en cualquier caso, al tratarse de un vínculo de carácter conceptual, en realidad no se estaría ante un razonamiento probatorio, sino más bien frente a una interpretación o calificación de hechos (2013: 44) ${ }^{39}$.

Como puede verse, las características de este género de garantías las tornan inviables para servir de enlace en una inferencia relativa a medidas cautelares penales, en donde la Corte Interamericana de Derechos Humanos ha sido enfática sobre la necesidad de fundamentar adecuadamente las resoluciones que puedan afectar derechos humanos ${ }^{40}$, así como verificar la existencia del periculum libertatis a partir de las circunstancias del caso concreto y no a través de presunciones ${ }^{41}$.

36 «(...) el argumento determinante para descartar las presunciones iuris, en cualquier versión, como argumentos aptos para dar por acreditada la peligrosidad procesal tal que el encarcelamiento cautelar es indispensable, está en que esta clase de presunciones no son prueba en absoluto» (Dei VeCCHI 2015a: 5-6).

37 «El indicio, por tanto, no es equivalente a una presunción sino que constituye, insistimos, el hecho base de la presunción» (Miranda Estrampes 1997: 227).

38 «(..) su idoneidad inferencial en términos probatorios dependerá de que sean aptos como datos indiciarios, lo cual requerirá de la presencia de un respaldo fáctico justificado. En otras palabras, es insoslayable una fundamentación empírica, y no normativa, que cimiente la regla de paso del dato indiciario a la pretensión, tal que esa regla constituya una genuina máxima de experiencia» (DeI VeCCHI 2015b:147). Desde una perspectiva similar, Hunter Ampuero habla de indicios tipo, enfatizando que «deben funcionar como guías y no como reglas» (2015: 246).

39 En el mismo sentido: Dei VeCCHI, 2015a: 8.

${ }^{40}$ Cfr. CIDH. Caso Apitz Barbera y otros vs. Venezuela, sentencia del 5 de agosto de 2008, párrafo 78; Tristán Donoso vs. Panamá, sentencia del 27 de enero de 2009, párrafo 153; López Mendoza vs. Venezuela, sentencia del 1 de septiembre de 2011, párrafo 148. Vid. también: Llobet 2018.

41 Cfr. CIDH. Caso Norín Catrimán y otros vs. Chile, sentencia del 29 de mayo de 2014, párrafo 312. Se indica en esta resolución que «el peligro procesal no se presume, sino que debe realizarse la verificación de este en cada caso concreto, fundado en circunstancias objetivas y ciertas del caso concreto». 
Ahora bien, el uso excesivo de las medidas cautelares de alto impacto, como la prisión preventiva o los mecanismos electrónicos de seguimiento, podría deberse precisamente a la automatización en su aplicación ${ }^{42}$, correlativa a la asunción de presunciones o la definición de los riesgos, operación que simplifica muchísimo una decisión de este tipo, con lo que parece que, en consonancia con lo dicho por DeI VeCCHI, se trata de forzar argumentos basados en ciertas intuiciones comunes (2015a: 8), en donde el juez tendría más de gurú o nigromante, que de decisor racional.

Entonces, habiéndose mostrado que en el rubro objeto de este trabajo la garantía del razonamiento inferencial no puede tener la forma de una presunción iuris o una definición, queda por evaluar qué tipo de máximas de experiencia se pueden utilizar y, principalmente, cuál es (o debe ser) su respaldo.

\subsubsection{Máximas de experiencia}

Como ya se ha adelantado, las máximas de la experiencia son regularidades que constituyen a su vez la conclusión de una inducción ampliativa, probables en sentido inferencial, lo que implica que se basen en una inducción ampliativa sólida si se quiere que estas estén debidamente fundamentadas (GonZÁlez LAGIER 2013: 59). En ese sentido, se han delineado al menos cuatro modelos en que pueden fundarse las máximas de experiencia (TARUfFo 2010: 237-40): leyes científicas de carácter universal, de donde se sigue una inferencia bajo el modelo nomológico-deductivo que permite atribuir certeza deductiva a la conclusión; generalizaciones no universales con alto grado de probabilidad, de donde se sigue una inferencia bajo el modelo cuasi nomológico deductivo que permite atribuir certeza práctica a la conclusión; generalizaciones de sentido común (id quod plerumque accidit), las cuales aportan un grado de confirmación variable a la conclusión, pero no especialmente alto; y generalizaciones espurias (pseudoreglas), sin ningún fundamento empírico, sino más bien alimentadas por prejuicios.

Dado que las medidas cautelares, en especial la prisión preventiva, pueden afectar sensiblemente una variedad importante de derechos fundamentales del imputado ${ }^{43}$,

42 En el ámbito costarricense, de acuerdo con el II Informe sobre el Estado de la Justicia, entre los ańos 2005 y 2015, el 54.2 por 100 de las personas detenidas preventivamente correspondieron a causas ligadas a la narcoactividad, concluyéndose en dicho informe que en las infracciones a la Ley de Psicotrópicos la prisión preventiva es casi automática, a pesar de que la cantidad de condenas es baja en ese tipo de casos (un 13 por 100 del total de condenas entre 2010 y 2015), aunado a que, de una muestra aleatoria de 159 expedientes en los que se dictó prisión preventiva en 2016, en despachos de la Gran Área Metropolitana, solamente en un 8 por 100 de estos asuntos las personas decisoras resolvieron de forma distinta a la peticionada por el ente fiscal, incluyendo un caso en que se solicitó una medida no privativa de libertad, pese a lo cuál la jueza dictó prisión preventiva (2017: 82-83).

43 No solamente se trata de la libertad ambulatoria. El estado de las prisiones en la mayoría de los países latinoamericanos es deplorable, con alarmantes niveles de hacinamiento. En Costa Rica, para el año 2020, se ha establecido un hacinamiento carcelario superior al 40 por 100 encontrándose cárceles 
es claro que el estándar de prueba requerido, tanto para la corroboración del fumus commissi delicti como del periculum libertatis, debe ser especialmente alto, lo que deriva de la vigencia del principio de proporcionalidad y se refleja en la excepcionalidad de la prisión preventiva, regulada convencionalmente y recogida en la mayoría de las codificaciones de los países latinoamericanos, aunque se trate en realidad de una excepcionalidad de papel, que no se condice con la realidad de nuestras prisiones y la práctica judicial imperante, según se ha visto ${ }^{44}$.

Por tanto, frente a un estándar de prueba riguroso es menester contar con inferencias debidamente construidas y fiables en lo tocante a su conclusión. Pero ¿cómo hacemos eso en hechos prospectivos? En el siguiente capítulo se valuarán algunas opciones para otorgar respaldo a la garantía en esta tipología de hechos.

\section{EL BACKING DEL WARRANT EN LOS HECHOS FUTUROS}

En este punto es posible afirmar que los hechos prospectivos, en sentido estricto, no son susceptibles de ser probados, en tanto no se puede corroborar algo que no ha sucedido. No obstante, siendo imprescindible dotar de contenido epistémico a la hipótesis probabilística que constituye el riesgo de ocurrencia de un evento ${ }^{45}$, es preciso establecer si es viable en la actualidad predecir la conducta humana, con suficiente fiabilidad como para afectar la esfera de libertades y derechos de un sujeto determinado.

La respuesta a dicha interrogante podría encontrarse en la psicología cognitiva y la estadística o en la inteligencia artificial, disciplinas que se encuentran íntimamente relacionadas pero que se analizarán de manera independiente para brindar mayor claridad, en tanto la expresión de cada una estas áreas de conocimiento presentan especiales limitaciones, que pueden tornar cuestionables las conclusiones a las que se arribe.

con niveles superiores al 100 por 100 de sobrepoblación (Informe, 2020:182-183). Esas condiciones implican un riesgo a la salud de los reclusos, además de la afectación a su derecho al trabajo, su entorno familiar, etc.

44 En cuanto a medidas cautelares diversas a la prisión o la vigilancia electrónica, parece evidente que el estándar de prueba sea menor, no obstante, la estructura del razonamiento inferencial es la misma, pues en cualquier caso debe partirse de la "prueba» de hechos prospectivos.

45 Hablamos acá del periculum libertatis como peligrosidad de segundo orden, pues en cuanto al fumus commissi delicti su tratamiento es mucho más simple, al coincidir su justificación parcialmente con la justificación de la decisión final, la cual esta constituida por hechos retrospectivos. De igual manera, si se asume el periculum libertatis como una fórmula de peligrosidad de primer orden (lo que no se condice con la regulación normativa actual en el CPP costarricense y en la mayoría de las codificaciones de los países latinoamericanos), los problemas se reducen, ya que existen máximas de experiencia, como se verá más adelante, que permitirían establecer una inferencia mucho más sólida. 


\subsection{La psicología cognitiva y la estadística}

La psicología cognitiva se ocupa de la «explicación de la conducta a entidades mentales, a estados, procesos y disposiciones de naturaleza mental, para los que se reclama un nivel de discurso propio» (Pozo 2006: 42), lo que permitiría, en principio, conocer si el comportamiento del individuo está determinado por tales representaciones mentales ${ }^{46} \mathrm{y}$, en esa medida, anticipar eventos.

Pese a que los procedimientos que se utilizan para estimar la probabilidad de que se genere cierto comportamiento en el futuro pueden aplicarse a una gran variedad de contextos jurídico-penales, desde la aplicación, mantenimiento o cese de beneficios carcelarios, medidas de seguridad post-delictuales, hasta medidas cautelares como la prisión preventiva u otras, en la actualidad la mayoría de los estudios especializados se han centrado en la valoración del riesgo de violencia en diferentes escenarios (violencia de pareja, en adolecentes, etc.) ${ }^{47}$, siendo más bien escasa su aplicación en escenarios judiciales incipientes como los relacionados con las medidas precautorias, en parte quizá por la premura con que debe resolverse la situación jurídica del investigado, lo que tornaría impracticable una pericia sobre este en tan corto tiempo.

Al margen de lo señalado, es claro que la virtualidad práctica del conocimiento que se genere desde la psicología cognitiva no depende en absoluto de su utilidad actual, por lo que la información que se obtenga con respecto a otro tipo de riesgos futuros puede brindar luz sobre su potencialidad en el área objeto de este ensayo ${ }^{48}$.

En los últimos lustros se han afinado y estandarizado una significativa variedad de instrumentos con capacidad predictiva del comportamiento violento futuro. Por ejemplo, solamente en cuanto al riesgo de violencia contra la pareja, potencialmente

46 LACHMAN y Butterfield han considerado que «unas pocas operaciones simbólicas relativamente básicas, tales como codificar, comparar, localizar, almacenar, etc., pueden, en último extremo, dar cuenta de la inteligencia humana y la capacidad para crear conocimientos, innovaciones y tal vez expectativas con respecto al futuro" (citado por: Pozo 2006: 42). Sin embargo, debe decirse que algunos autores como Rrvière consideran el concepto de psicología cognitiva como «un caso más de categoría natural o mal definida dentro de las escuelas psicológicas» (citado por: Pozo 2006: 42), aunque para efectos de este trabajo es absolutamente prescindible una fina delimitación conceptual, bastando con que se tenga claro que involucra también una lectura del comportamiento humano, con miras a prever conductas futuras. Sobre algunos aspectos históricos de la disciplina vid. Méndez Paz 2015.

47 Pueyo y Echeburúa destacan el HCR-20 y la PCL-R para la violencia interpersonal grave, la SARA y la EPV en el caso de la violencia contra la pareja, el SVR-20, en casos de violencia sexual, y el SAVRY, en supuestos de violencia juvenil (2010: 403).

48 De más está recordar que la evaluación del riesgo de violencia si tiene incidencia directa en lo tocante al peligro de obstaculización, cuando la prueba en riesgo sea testimonial, pues entran en juego posibles acciones violentas para «desanimar» al testigo, provocando incluso su muerte, siendo esta la razón más usual cuando se alega este riesgo procesal, alcanzando en Costa Rica más de un 34 por 100 del total de las gestiones de prisión preventiva en el 2016, frente a un 1.9 por 100 relacionado con otro tipo de pruebas. Vid. III Informe Estado de la Justicia, 2020: 283. 
relevante para sostener una inferencia relacionada con la causal de obstaculización de prueba testimonial, se pueden mencionar las siguientes escalas: El Danger Assessment Tool (DA), la Femicide Scale, la Spousal Assault Risk Appraisal Guide (SARA), la Ontario Domestic Assault Risk Assessment (ODARA) y la Escala de Predicción de Riesgo de Violencia contra la Pareja (EPV) ${ }^{49}$ (Echeburúa et al. 2010: 1055), mientras que en delincuencia juvenil se cuenta con el IGI-J, el Youth Level of Service/Case Management Inventory, el YLS/CMI, entre otros (GARRIdo y GonzÁlez 2018: 5) ${ }^{50}$.

Esto ha significado una transición de la valoración de la peligrosidad del individuo hacia la evaluación del riesgo de violencia (Muñoz Vicente y López-Ossorio 2016: 130; Pueyo y Echeburúa 2010: 403) ${ }^{51}$, aunque parece que existe cierto acuerdo en cuanto a las limitaciones predictivas de los instrumentos, principalmente en virtud de la inestabilidad, variedad y simultaneidad en la ocurrencia de los factores de riesgo, aunado a la relativa infrecuencia de la conducta violenta (Echeburúa et al. 2010: 1054; Pueyo y Echeburúa 2010: 403-4; Romeo Casabona 2018: 45).

El punto de partida en la investigación rigurosa de los componentes de predicción de la conducta se suele ubicar en el modelo integrado de conducta delictiva propuesto por Andrews y Bonta en 1994 (Muñoz Vicente y López-Ossorio 2016: 132), quienes enfatizan sus estudios en la existencia de distintos factores de riesgo/protección. Los factores de riesgo incorporan elementos estáticos ${ }^{52}$ y dinámicos ${ }^{53}$, mientras que los factores de protección imbuyen aquellas condiciones que morigerarían los primeros. Precisamente de su interacción se deriva la posibilidad de predicción de la conducta $^{54}$.

49 SARA y EPV han sido validadas para su uso en España.

50 Sobre los factores dinámicos en el comportamiento de delincuentes juveniles puede verse: NAVARRO y PASTOR, 2017.

51 Para una perspectiva histórica vid. EsBec, 2003. La diferencia radica en que para valorar el riesgo es prescindible establecer las causas de la violencia. De esta manera, se entiende que la peligrosidad es tendencial del sujeto, mientras el riesgo se concentra en la probabilidad del peligro futuro, lo que implica que el riesgo de violencia se conciba como un constructo variable y específico, mientras el peligro sería estático y genérico (Pujol Robinat et al. 2014: 17). Por su parte, Pueyo y Redondo afirman que «el desarrollo de la psicología criminológica ha mostrado que la capacidad predictiva de la peligrosidad es limitada y su uso poco eficaz para los profesionales que toman decisiones prospectivas en contextos forenses, clínicos o penitenciario» (2007: 157). MARTínez GARAY sostiene una visión crítica sobre la distinción, al estimar que «desde luego que el concepto de peligrosidad es tremendamente impreciso, pero por desgracia seguramente ocurre algo parecido con el de valoración del riesgo» (2014: 9). Cfr. Romeo Casabona, 2018: 40-42.

52 Condiciones bio-psico-socioculturales de difícil variación (cuestiones de carácter hereditario, victimización, traumatismos, etc.).

53 Condiciones bio-psico-socioculturales que si son susceptibles de modificación (desempleo, valores, psicopatologías reversibles, etc.).

54 Debe anotarse que en la actualidad se parte de un concepto de causalidad probabilística, con lo que se superan los modelos deterministas y monocausales de antaño (Muñoz Vicente y LópezOssorio 2016: 131). 
En cuanto a la metodología utilizada para la predicción del riesgo, la psicología cognitiva utiliza en la actualidad dos modelos diversos ${ }^{55}$, el modelo clínico y el modelo actuarial. El modelo clínico (también llamado profesional estructurado o clínico estructurado), se basa en la perspectiva ideográfica (particular) y se enfoca en los factores dinámicos del riesgo, pero su debilidad radica en poseer un «elevado margen de subjetividad al descansar el juicio pronóstico en el profesional que realiza la evaluación» (Muñoz Vicente y López-Ossorio 2016: 135), por lo que la fiabilidad del resultado dependerá de la competencia del experto y los posibles sesgos que presen$\mathrm{te}^{56}$, aunado a que se trata de un aspecto que no es intersubjetivamente controlable.

Se ha llegado a afirmar que las predicciones de riesgo de violencia a partir del modelo clínico estructurado mejoran significativamente los pronósticos en poblaciones penitenciarias, enfermos mentales, agresores de pareja y sexuales, asimilándose su validez a los pronósticos obtenidos en otras áreas profesionales como la meteorología (Pueyo y Echeburúa 2010: 408) ${ }^{57}$, lo que podría ser no muy esperanzador, tomando en cuenta las implicaciones del riesgo de error en el área que nos ocupa, mucho mayores que las relacionadas con llevar o no un paraguas a la oficina.

Por su parte, los modelos actuariales o estadísticos se fundan en una perspectiva nomotética (general) y se concentra en los factores estáticos. Aunque tienen la virtud de eliminar el componente subjetivo presente en los modelos clínicos, su mayor debilidad radica, conforme lo señalan MuÑoz y López, en la posibilidad de «sobreestimar el nivel de cientificidad del proceso decisional» (2016: 134), inobservando que los valores promedio de un grupo reflejan en muy escasa medida el posible comportamiento de un individuo concreto, debido precisamente a la heterogeneidad intragrupo, es decir, se trata de una excesiva simplificación de los procesos complejos y multifactoriales que intervienen en la determinación de la conducta de una per-

55 Hasta los años ochenta del siglo pasado se utilizó un modelo no estructurado que se centraba en la psicopatología y se apoyaba exclusivamente en la impresión clínica del experto. Sin embargo, la deficiente capacidad predictiva y el alto nivel de subjetividad provocó sus desuso en la actualidad (Muñoz Vicente y López-Ossorio 2016: 133). Cfr. Pueyo y Echeburúa, 2010:404. Esbec por su parte identifica 5 etapas en la valoración de la peligrosidad-riesgo: a. juicios clínicos no estructurados (hasta 1970); b. investigación empírica (durante la década de los 70 y 80); c. métodos exclusivamente actuariales (a mediados de los 90’s); d. método mixto, clínico-actuarial (año 2000); y e. árbol de decisiones (en la actualidad) (2003: 52-64). Martínez GaraY reconoce tres métodos para la predicción de la peligrosidad: a. actuarial; b. clínico no estructurado (también llamado por la doctrina alemana como método clínico idiográfico o empírico-individual; y c. clínico estructurado (2014: 15-18). No obstante, para los efectos de este ensayo, se utilizará una clasificación simplificada dual que agrupe las evaluaciones que incorporen mecanismos actuariales, sean estos puros o con cierta incidencia del criterio de un experto, prescindiendo del modelo clínico no estructurado, por estar este último ampliamente desacreditado (Martínez Garay 2014: 18).

56 Incluyendo el sesgo de representatividad, el de inmediación y disponibilidad, el de anclaje y ajuste, el retrospectivo, el de confirmación y el llamado miedo social al falso negativo (MuÑoz VICENTE y López-Ossorio 2016: 135). Cfr. Nieva Fenoll, 2010: 120-128, Sunstein, 2012: 61-63.

57 Cfr. con amplia bibliografía sobre el particular, Martínez Garay 2014: 27. 
sona $^{58}$. Tal y como apunta MARTínez GARAY, los modelos actuariales suponen la validez de un razonamiento analógico pese a que, como resulta evidente, no ofrecen una predicción individual (2014: 16) ${ }^{59}$.

Lo anterior significa que el riesgo de un falso negativo o un falso positivo será tanto mayor cuanto mayor sea la heterogeneidad de los sujetos dentro del grupo de referencia. Estos aspectos son coincidentes con los problemas relativos a la utilización de la estadística como garantía de los datos, visualizados desde el derecho. Por ejemplo, refiere Dei VECCHI, al analizar el sistema estadounidense y la aplicación del bail denial (2015b:152-156), que efectuar una prognosis de la conducta humana, aún disponiendo de información estadística que relacione ciertos datos con la concreción de un peligro procesal, resulta extraordinariamente complejo.

En el mismo sentido, se han señalado tres problemas concretos en cuanto a la información estadística: no se dispone de esa información; no se dispone de un mecanismo para determinar cuál es la clase de referencia (hombres, pobres, con estudios universitarios, solteros, madres, etc.), siendo las posibles combinaciones de factores infinita; y aún disponiendo de información estadística, esta no dice nada sobre el caso concreto a juzgar (Ferrer Beltrán, 2018b: 149-150) ${ }^{60}$.

Volviendo a la perspectiva eminentemente psicológica, el problema que se encuentra en cualquiera de los dos modelos analizados es que las correspondientes debilidades anotadas provocan un incremento significativo del número de falsos positivos ${ }^{61}$, pues aunque el valor predictivo negativo presenta márgenes altos de acierto, el valor predictivo positivo no alcanza el cincuenta por ciento, de acuerdo con los metaanálisis realizados recientemente (MuÑoz Vicente y López-Ossorio 2016: 137-38).

58 Un ejemplo interesante de error en la aplicación de instrumentos actuariales lo aportan MuÑoz y López, quienes refieren el caso de Jeffrey DAHmer, el conocido "Canibal de Milwaukee», en donde, de haberse aplicado un modelo actuarial (el RRASOR), habría sido catalogado como de bajo riesgo de recidiva sexual (2016:135). Sobre este mismo caso también puede verse: EsBEC, 2003: 58.

59 La autora hace un interesante análisis de los casos «Baxstrom» y «Dixon», resueltos por el Tribunal Supremo Federal de los Estados Unidos de América, así como sobre otras investigaciones realizadas en Alemania, en donde se constatan tasas altísimas de falsos positivos con la aplicación de mecanismos actuariales, que alcanzan hasta el 97\% de falibilidad, lo que evidencia una notoria sobreestimación de la peligrosidad. Sin embargo, también se observa un alto grado de acierto con respecto a la conclusión de que un sujeto es poco peligroso (2014: 19-23). Vid. también: Martínez Garay 2016: 17.

60 Se trata de la llamada falacia de la división (Martínez Garay 2014: 42). Martínez GaraY destaca que el margen de error grupal (intervalo de confianza) presente en los instrumentos actuariales es completamente diverso al correspondiente a la valoración de la predicción individual (intervalo de predicción), siendo este último siempre mayor que el primero, alcanzando valores que pueden ubicarse entre 1 por 100 y 99 por 100 con lo que el instrumento «pierde toda capacidad discriminadora, en la medida en que estos márgenes de error tan amplios se solapan por completo» (2014: 41).

61 MuÑoz y López refieren recientes metaanálisis que demostraron una mínima diferencia entre la capacidad predictiva de ambos modelos (2016: 135). Cfr. Pueyo y Redondo, 2007: 169, quienes afirman que si se ha constatado una mejora en la eficacia predictiva de los métodos clínico-estructurados. 
Por otra parte, en múltiples investigaciones realizadas, MARTínez GARAY ha comprobado que los pronósticos de peligrosidad sustentados en mecanismos actuariales ocultan importantes tasas de falsos positivos (2014, 2016, 2018; MarTínez GaraY y Montes Suay 2018), debido a diversos factores ${ }^{62}$. Algunos de estos son atinentes a las limitaciones propias de los métodos estadísticos y la forma en que se presentan los resultados en sede judicial, dada la altísima complejidad de los instrumentos de predicción de peligrosidad, aun para los expertos en la materia.

Desde esta perspectiva, la autora enfatiza la relevancia de diferenciar con claridad la sensibilidad (capacidad para detectar a las personas que poseen la característica buscada), la especificidad (capacidad para detectar a las personas que no poseen la característica buscada) y el valor predictivo del instrumento (determina cuántos de los sujetos identificados con cierta característica por el instrumento efectivamente la poseen), de forma que, mientras los dos primeros aspectos tienen una orientación retrospectiva, el último tiene una orientación prospectiva (MARTínez GARAY y MoNtes SuAY 2018: 13-16).

Aunque el valor predictivo es el que más interesa en el ámbito jurídico (MarTíNEZ GaraY 2014: 36), algunas investigaciones ocultan ese dato y presentan valores relativos a la sensibilidad o la especificidad, los que suelen ser diametralmente diversos al primero y, en tal sentido, pueden llevar a error al operador jurídico, en cuanto a la apreciación del grado de acierto del mecanismo ${ }^{63}$.

Adicionalmente, la llamada curva $\mathrm{ROC}^{64}$ es en la actualidad la medida estándar para establecer la capacidad predictiva de los mecanismos actuariales de evaluación de riesgo, a pesar de que la información que deriva de esta (área bajo la curva) es una medida de riesgo relativo que nada dice sobre el riesgo absoluto o sobre el valor predictivo, lo que puede llevar a severos errores en la apreciación del nivel de fiabilidad de los resultados ${ }^{65}$. Además, no se deben inobservar las cuestiones propias de la política criminal, ya que «todo apunta a que cuando se trata de adoptar medidas sobre sujetos eventualmente peligrosos predomina el deseo de minimizar las 'omi-

62 A continuación, se hará un sucinto repaso sobre algunas nociones trascendentales para entender los vicios que pueden presentarse en la aplicación de este tipo de instrumentos actuariales, para cuyo abundamiento se remite a la bibliografía ya mencionada.

63 Martínez Garay también destaca otros elementos como parte de las limitaciones de los métodos estadísticos, por ejemplo, la tasa de prevalencia del fenómeno, ya que, de acuerdo con la fórmula de Bayes, «si la sensibilidad y la especificidad permanecen constantes, cuanto más baja es la prevalencia de un fenómeno en una población, tanto mayor será la tasa de falsos positivos que se obtenga al predecirlo» (2014: 30), los márgenes de error, la traslación de resultados grupales a individuos y la diferencia entre el riesgo absoluto y el riesgo relativo (MarTínez GaraY 2016: 16-23, 2018: 12-13).

64 Acrónimo de Receiver Operating Characteristics.

65 «puede haber instrumentos con valores altos de área bajo la curva ROC, superiores al 80\%, pero cuyo valor predictivo no llegue ni siquiera en el mejor de los casos al 50 por 100 (...) Hay que tener en cuenta que la curva ROC se construye sobre los valores de sensibilidad y de especificidad, de modo que tiene -igual que ellos- una orientación fundamentalmente retrospectiva, y no prospectiva» (MARTínez Garay y Montes Suay 2018: 25). 
siones', aunque ello sea a costa de asumir un importante número de 'falsas alarmas'» (Martínez Garay 2014: 32).

Se suman a las limitaciones propias de las metodologías aplicas por la psicología cognitiva algunas condiciones que podrían llamarse estructurales, relacionadas con el sistema de administración de justicia penal y la etapa en que se requeriría la aplicación de los instrumentos analizados. En primer lugar, debe apuntarse que para la realización de este tipo de pericias es imprescindible contar con una enorme cantidad de información, relativa al expediente judicial (incluyendo el record criminal que pudiera tener el sujeto), historial médico, entrevistas, exploración física y psicopatológica, pruebas psicométricas, entre otras (Pujol Robinat, Mohíno Justes, y GómEZ-Durán 2014: 21-22), lo que sería virtualmente imposible de obtener dada la premura con que debe ser resuelta una solicitud de medidas cautelares y la saturación de los servicios de psicología forense institucionales.

Otro inconveniente de especial relevancia es que la escala, guía o formulario que utilice el profesional en psicología en la evaluación debe estar validado en el contexto específico en que se vaya a utilizar, lo que puede variar de un país a otro, pero también incluso dentro del mismo territorio, en atención a factores socioculturales y educativos que son extraordinariamente volubles ${ }^{66}$.

Pero uno de los problemas más significativos, sin duda alguna, es el de la selección de los factores de riesgo que se consideren empíricamente válidos, ya que los mismos pueden responder a estereotipos o a la propia selectividad de los sistemas penales ${ }^{67}$, que se dirige a «la raza distinta que tiene el privilegio de poblar los presidios y las cárceles» (Foucault 2003: 262). De acuerdo con estudios realizados por MandRaCCHIA y Morgan (2011) a partir de la revisión de 595 causas con delincuentes adultos encarcelados, intentaron identificar aquellos con una prognosis criminógena sobre la base de variables como la salud mental, factores demográficos, entre otros, logrando identificar que las personas más jóvenes, con menor educación formal, solteros, afrodescendientes e hispanos, mantenían mayores índices de criminogenic cognitions ${ }^{68}$.

Lógicamente, si se parte de este tipo de indicadores, los instrumentos o guías que apliquen los expertos tendrán una cualidad de autopoiesis, que tenderá a perpetuar la desigualdad estructural de nuestras sociedades, con franca lesión de los derechos

${ }^{66}$ Por ejemplo, las guías SARA y EPV se encuentra validadas en España, ya que la situación cultural Europea es disímil a la estadounidense con respecto a indicadores como el uso de armas y la composición familiar, elementos que pueden ser determinantes en la precisión del pronóstico (ECHEBURÚA et al. 2010: 1055).

67 El III Informe sobre el Estado de la Justicia en Costa Rica seńala que «el aumento en la pena privativa de libertad responde a entornos de exclusión y estigmatización, donde se victimiza a las poblaciones en mayor riesgo social a través de una selectividad estructurada del sistema penal» (2020: 185). Adicionalmente, sobre el llamado self-fulfilling prophecy puede verse: MARTínez GARAY 2014: 5.

68 Romeo Casabona identifica un aspecto adicional con algunas preguntas que incorporan las guías, mismas que no guardan relación mediata o inmediata con el estilo de vida o el entorno familiar, con proclividad o que de alguna forma pudiese ser considerado como un factor criminógeno (2018: 44). 
fundamentales de las poblaciones más vulnerables ${ }^{69}$, de manera que «lo que hace relevante a la estadística no es más que el fin que se proponen quienes la invocan» (Dei Vecchi 2015a: 7).

\subsection{La inteligencia artificial}

En términos generales, las críticas planteadas en contra del uso de la psicología cognitiva y la estadística para predecir conductas con la fiabilidad suficiente para propiciar una respuesta penal, es trasladable a los mecanismos, en apariencia más refinados, de la inteligencia artificial, en tanto la valoración de riesgos mediante cualquier tipo de software se alimenta de variables estadísticas dispuestas por seres humanos ${ }^{70}$.

Ya desde el propio ámbito de la psicología se ha advertido sobre la «tendencia a sobrevalorar desde el contexto jurídico todo aquello que lleva la etiqueta de ciencia» (Muñoz Vicente y López-Ossorio 2016: 130) ${ }^{71}$, lo que conlleva un enorme riesgo para que se defiera la resolución de asuntos trascendentales en programas computarizados que no generan, al menos con el desarrollo tecnológico actual, mayores garantías que la aplicación de una guía clínica estructurada como las ya analizadas, con el único aspecto positivo atinente a la eliminación de una buena parte del componente subjetivo en la aplicación del instrumento ${ }^{72}$.

Como se ha indicado, los sistemas de inteligencia artificial para la predicción del riesgo incorporan modelos estadísticos y matemáticos, clasificando al individuo en ciertos grupos prototípicos a los que se les asigna determinado grado de riesgo, de forma completamente despersonalizada, sin efectuar un pronóstico conductivo psicológico concreto, de manera similar a la evaluación de riesgo que se realiza en otras áreas de la actividad humana, como la industria del seguro y la industria biotecnológica (Romeo Casabona 2018: 43).

69 Sobre este aspecto se volverá en el siguiente apartado, al desarrollar los instrumentos de inteligencia artificial.

70 «En esencia no es, por consiguiente, un método diferente, sino una herramienta tecnológica nueva que trataría de forma "inteligente" los algoritmos que sirven de base al procedimiento actuarial» (Romeo Casabona 2018: 47).

71 Martínez GaraY advierte sobre el "peligro de que la sofisticación estadística y la consideración como 'científicas' de las herramientas de valoración del riesgo favorezca el que se extendiera la ilusión de que su uso convierte en meras decisiones técnicas los seculares problemas valorativos que siempre han estado implicados, y lo siguen estando, en toda decisión que suponga aplicar consecuencias penales a un individuo basadas en un juicio acerca de su comportamiento en el futuro: nos referimos a la ponderación entre el respeto a los derechos fundamentales del reo, por un lado, y las necesidades de prevención por el otro" (2018: 8).

72 Nieva refiere que los criterios estadísticos son aptos para componer una herramienta de inteligencia artificial, pero visualiza idénticos reparos en su utilización, relacionados con la pérdida de detalles del caso concreto y la dificultad que entraña evaluar riesgos a partir de la observación de circunstancias externas, por lo que «a una aplicación de inteligencia artificial habría que pedirle algo más» que la labor que realizan actualmente los seres humanos (2018: 63). 
Un caso muy interesante, con respecto al mecanismo denominado $\mathrm{COMPAS}^{73}$, permite ilustrar algunos de los aspectos que se han criticado a lo largo de este ensayo. Se trata de la sentencia del Tribunal Supremo de Wisconsin denominada State v. Loo$m i{ }^{74}$. En este fallo el alto tribunal evaluó la constitucionalidad del uso de logaritmos procesados informáticamente, a través de un software de inteligencia artificial, para sostener una sentencia condenatoria, señalando dicho órgano decisor que no resultó conculcado el debido proceso por el hecho de que no se le brindó a las partes la posibilidad de conocer cómo se realizó realmente el procesamiento de los algoritmos, dado que la empresa Northpointe Inc., dueña del sistema, no estuvo de acuerdo en revelar esa información y el tribunal decidió darle primacía al derecho de propiedad intelectual sobre los derechos fundamentales del encartado (Romeo Casabona 2018: $48-50)^{75}$.

En la apelación del fallo, la defensa argumentó, entre otras cosas, que la utilización de la herramienta colisionaba con el derecho del imputado a obtener una sentencia individualizada (pues, como se ha visto, el software se alimenta de indicadores estadísticos) así como la discriminación por género, pues uno de los factores tomados en cuenta era ese rubro; no obstante, la apelación fue rechazada por el Tribunal y, ante la posterior gestión de revisión del fallo, el Tribunal Supremo de los Estados Unidos de América denegó la admisión del recurso, el 26 de junio de 2017.

En consonancia con las críticas esgrimidas contra las guías actuariales, con respecto a COMPAS se ha denunciado que muchos de los factores que lo integran son eminentemente racistas o clasistas (Nieva Fenoll 2018: 69) ${ }^{76}$, por lo que, de acuerdo con lo sostenido por Romeo Casabona, la fiabilidad de estos mecanismos hacen que su utilización en la actualidad sea claramente prematura, máxime cuando se ha podido corroborar que existen contradicciones entre sus resultados y los obtenidos con la utilización de guías aplicadas por un ser humano; esto no excluye que ciertos mecanismos de este tipo se usen como criterios complementarios o confirmatorios, pero nunca como un aspecto definitorio de una fuente de riesgo (2018: 52-55).

${ }^{73}$ Perfiles de Gestión de Delincuentes Correccionales para Sanciones Alternativas (Correctional Offender Management Profiling for Alternative Sanctions).

${ }^{74}$ Un desarrollo más amplio sobre la sentencia State v. Loomis, 881, N.W.2d 749, 7532 (Wis, 2016) se puede ver en: Nieva Fenoll 2018: 67-75; Slobogin 2019: 114-116; Romeo Casabona 2018: 48-55; Martínez GaraY 20 I 8.

75 "But rather than demanding such information so that fit, validity and fairness could be analyzed, the court lamely concluded that trial courts could continue to use the COMPAS in connection with sentencing as long as judges are cognizant of these limitations and do not make the risk score so produced determinative of whether the offender is incarcerated or receives an enhanced sentence» (SLOBOGIN 2019: 115).

${ }^{76}$ Para mayor claridad, con respecto a este argumento, puede consultarse la Practitioner's Guide to COMPAS Core en: http://www.northpointeinc.com/downloads/compas/Practitioners-Guide-COMPAS-Core-_031915.pdf Visitada el 18 de junio de 2020. Vid. también: Larson, Mattu, Kirchner, y ANGWIN, 2016, quienes lograron confirmar, a partir del estudio de más de 10000 casos, que «that black defendants were far more likely than white defendants to be incorrectly judged to be at a higher risk of recidivism, while white defendants were more likely than black defendants to be incorrectly flagged as low risk». 
Con todo, siguiendo a Martínez GaraY, en los Estados Unidos la implementación de la evidence based sentencing continúa extendiéndose y, a pesar de que en el caso State v. Loomis se estableció que este tipo de mecanismos no pueden ser empleados para decidir el encarcelamiento de una persona o para determinar la severidad de la sentencia, es decir, no pueden constituir las valoraciones de riesgo el elemento determinante en la resolución ${ }^{77}$, es altamente probable que este tipo de software provoque un sesgo de anclaje en el decisor, en tanto la privación de libertad "puede hacerse con la conciencia un poco más tranquila si los jueces pueden confiar en que su intuición está corroborada por una valoración de riesgo científicamente fundada» (Martínez Garay 2018: 496), pese a la escasa fiabilidad que pueda tener el instrumento, lo que desaconsejaría su implementación.

\section{3. ¿Cuál es el rendimiento de la estadística?}

A lo largo de los capítulos precedentes se han expuesto algunas advertencias sobre la utilización en sede judicial de mecanismos predictivos conductuales. El lugar común que se ha observado es el uso de ciertas guías o formularios, que pueden aplicarse de manera pura, es decir, con escasa participación de seres humanos, o bien por medio de expertos en psicología cognitiva o a través de programas de inteligencia artificial. Como ocurre muchas veces en el ámbito jurídico, parece que se ha confiado de más en estos instrumentos, habida cuenta de la escasa fiabilidad que tienen sus resultados, «[n]o se olvide que al estar ocupándonos del comportamiento humano futuro, siempre deberá situarse, por su propia naturaleza, en el ámbito de lo conjetural, aunque pueda serlo en un grado mayor o menor» (Romeo Casabona 2018: 46).

Sin embargo, estimo que no es posible desestimar sin más el andamiaje epistémico que puede provenir de la estadística, con miras en dar sustento a las inferencias que se construyan para tener por probado un enunciado relativo a hechos prospectivos. Por otra parte, uno de los grandes problemas de la cultura jurídica latinoamericana es la inexistencia de registros empíricos sobre el funcionamiento de las instituciones, no solamente para poder abordar con solvencia reformas o mejoras que optimicen los resultados que se requieren, sino también para modular ciertas prácticas incorrectas o disfuncionalidades de estas. El caso de la medida cautelar de prisión preventiva sin duda es uno de los más llamativos, si se toman en cuenta los elevadísimos índices de hacinamiento carcelario presentes en toda la región, de cuyo total una proporción significativa corresponde a presos sin condena.

En Costa Rica desde hace algunos años se han venido incorporando en los informes sobre el estado de la justicia cada vez más datos relevantes que permiten tener una

77 En realidad, la sentencia es confusa, pues establece que el presentence investigation report debe advertir sobre las limitaciones seńaladas e informar otros aspectos sobre el funcionamiento del software, pese a lo cual avala la utilización de COMPAS en el caso concreto. 
imagen más clara de la forma en que opera la administración de justicia en la realidad. Pero este aspecto positivo desgraciadamente no ha tenido réditos a nivel práctico, con lo que esta valiosa información es escasamente conocida y se ha convertido en letra muerta. A continuación, se presentarán algunos datos estadísticos interesantes, provenientes de los estudios mencionados ${ }^{78}$, así como de una investigación privada realizada para los fines de este trabajo, que, según creo, también pudieran ser útiles para la determinación de la procedencia de una medida cautelar, siempre que su uso sea prudente y no se conviertan en parte del frecuente fetichismo hacia las cifras, que en ocasiones permea nuestra actividad ${ }^{79}$.

Uno de los aspectos más preocupantes es que el índice de Estado de derecho ${ }^{80}$ muestra que, en 2018, el sistema penitenciario fue el peor evaluado con relación a todos los indicadores asociados a la justicia penal en Costa Rica, con una tasa de prisionalización mucho más alta que la de países con situaciones de mayor violencia y desigualdad social. Los niveles de sobrepoblación carcelaria están por encima del 40 por 100 (más del doble de lo establecido por los estándares internacionales), lo que significa que el hacinamiento es crítico.

De acuerdo con los datos recabados por el Ministerio de Justicia y Paz, en junio de 2019 se llegó al nivel más alto de hacinamiento penitenciario de los últimos dos años, existiendo establecimientos carcelarios con niveles de sobrepoblación superiores al 100 por $100^{81}$, además de registrarse un importante aumento del grupo de presos sin condena, que pasó de un 20,3\% en 2015 , a un 29,9 por 100 en 2019 , con respecto al total de la población penitenciaria costarricense.

Si bien entre 2010 y 2015 disminuyeron las personas con prisión preventiva por delitos contra la propiedad, se registró un aumento de los indiciados por infracciones a la Ley de Psicotrópicos, de forma que ambas categorías delictivas representaron el 65.7 por 100 del total de presos sin condena entre 2005 y 2015, con una característica muy llamativa: los delitos en los que es más frecuente la prisión preventiva registran menos condenas ${ }^{82}$.

${ }_{78}^{7}$ La información se ha tomado de: II Informe Estado de la Justicia 2017, III Informe Estado de la Justicia 2020. Puede accederse a esta información mediante la siguiente dirección web: https:// estadonacion.or.cr/

79 TARUfFo habla del síndrome de "lo que no se puede contabilizar no existe», de donde deriva la errónea idea de que lo que es susceptible de traducirse en cifras es más exacto y más racional que lo que no (2010: 248). En sentido similar, Martínez GaraY afirma que «[1]a creencia en que algo puede ser medido con precisión favorece la tendencia a considerarlo un fundamento admisible para una consecuencia jurídica» (Martínez Garay y Montes Suay 2018: 37).

80 De acuerdo con el World Justice Project.

81 El II Informe Estado de la Justicia (2017) advirtió sobre tres posibles causas del hacinamiento penitenciario: el aumento en las condenas, la creación de los tribunales de flagrancia y el uso excesivo de la prisión preventiva.

82 Particularmente alta es la proporción de indiciados por delitos contra la vida e infracciones a la Ley de Psicotrópicos, si se compara con las sentencias condenatorias por esas mismas causas. Por ejemplo, en las infracciones a la Ley de Psicotrópicos la prisión preventiva parece ser casi automática, 
Otro de los datos realmente interesantes es que la falta de arraigo (92.5 por 100) y la expectativa de pena muy alta ( 57.9 por 100$)$ son las dos causales más usuales para disponer la detención cautelar ${ }^{83}$, además de la magnitud del daño (45.3 por 100), la continuidad delictiva (43.4 por 100) y la «influencia sobre peritos y testigos» (34.6 por 100) o sobre la víctima o denunciantes (34 por 100).

En cuanto al perfil socioeconómico de la población privada de libertad en Costa Rica, mayoritariamente se trata de personas provenientes de estratos socioeconómicos bajos, generalmente hombres, jóvenes, costarricenses (87 por 100); el 51 por 100 se encontraba en condición de soltería, divorcio y viudez, mientras que el 49 por 100 en relaciones de unión, sea matrimonio o unión libre. También es notorio un predominio de niveles bajos de escolaridad ${ }^{84}$.

Por otra parte, en un estudio efectuado en la zona sur del país ${ }^{85}$, se ha podido obtener información también interesante. Por ejemplo, del total de casos ingresados al Ministerio Público, en un 23 por 100 se ordenó la libertad sin requerimiento jurisdiccional, en un 27 por 100 se requirió la aplicación de medidas cautelares no privativas de libertad, mientras que un 30 por 100 corresponde con solicitudes de prisión preventiva, una cifra que pudiera estimarse razonable, tomando en cuenta las cifras país vistas anteriormente ${ }^{86}$. De la cifra total, el 41.7 por 100 de los casos corresponden a cuestiones relacionadas con violencia sexual o violencia de género, el 6.8 por 100 a narcotráfico y el 18.4 por 100 específicamente a gestiones de prisión preventiva por casos de violencia de género, llamando la atención que en la totalidad de los casos por tráfico de drogas el Ministerio Público solicitó prisión preventiva, siendo rechazado el pedido en un 42.8 por 100 , una cifra alta si se compara con los datos generales en el país.

En cuanto al abordaje de las gestiones fiscales, el Juzgado Penal dictó prisión preventiva en un 21.3 por 100 de los casos, otro tipo de medida cautelar en el 31 por

pero la cantidad de condenas es ridículamente baja, representando un 13 por 100 del total de condenas entre 2010 y 2015 . Este dato concretamente debería de utilizarse a la hora de considerar probado el fumus commissi delicti, ya que este riesgo no es otra cosa que un pronóstico sobre la futura condena del encartado.

83 Concretamente estos datos fueron obtenidos a partir de un estudio aleatorio realizado a 159 expedientes en que se dictó prisión preventiva en 2016, en la meseta central del país.

${ }^{84}$ En los hombres, el 58 por 100 tan solo cuenta con primaria, completa o incompleta, un 28 por 100 con secundaria incompleta y un 5 por 100 de personas analfabetas, más del doble del promedio nacional. En las mujeres, el 58 por 100 tiene primaria completa o incompleta, un 28 por 100 secundaria incompleta y un 4 por 100 son analfabetas.

85 Específicamente en el II Circuito Judicial de la Zona Sur. Se trata de una adscripción territorial con predominio de delincuencia ligada a la narcoactividad, por ser una zona fronteriza y costera, así como delitos relacionados con violencia de género. La muestra se ha tomado del total de casos con personas detenidas en la Fiscalía durante el año 2019.

${ }^{86}$ El 19.4 por 100 de las causas ingresadas fueron tramitadas con incompetencia a otra localidad, lo que puede significar un sesgo importante, ya que en estas causas perfectamente se pudo solicitar prisión preventiva u otra medida diversa. 
100 de las gestiones y denegó la solicitud y ordenó la libertad en un 4.8 por 100 de los asuntos. Otro dato interesante es que de la cantidad total de personas en condición de rebeldía (no ubicables) y con orden de captura, ninguno corresponde a casos de narcotráfico, el 18.7 por 100 a delitos sexuales, el 34.3 por 100 a delitos contra la propiedad, solamente el 0.03 por 100 a delitos relacionados con violencia de género, mientras que el 59.3 por 100 corresponde a delitos con penas inferiores a los tres años de prisión, lo que permitiría al investigado obtener un beneficio de ejecución condicional de la pena y, eventualmente, no pasar un solo día en prisión.

¿Qué podemos concluir a partir de los datos que se han expuesto? En primer lugar, creo que se ha demostrado la relevancia que tiene tomar en cuenta los aspectos socioculturales, el tipo de variables, las características de la muestra, entre una pluralidad de factores que potencialmente pueden hacer que se alcancen resultados completamente disímiles, aún en una extensión territorial tan pequeña como la de Costa Rica, lo que se refleja con facilidad a partir de las divergencias de los resultados a nivel país, los que se obtuvieron a partir de una muestra aleatoria en el área metropolitana y los recabados en una zona rural. Esto implica, como se ha referido, que el carácter multifactorial y voluble de la conducta humana, además de cualquier sesgo en quien defina las variables o ejecute el muestreo estadístico, puede dar al traste con la potencialidad del instrumento, en términos de fiabilidad.

No obstante, la existencia de mecanismos refinados y validados desde la perspectiva de la psicología cognitiva, con todas las limitaciones que pudiesen tener, permiten generar algunos datos relevantes susceptibles de ser usados para sostener una inferencia en cuanto a hechos prospectivos ${ }^{87}$. Debe recordarse que es preciso descartar como garantía de la inferencia en las medidas cautelares, principalmente cuando se trate de prisión preventiva o monitoreo electrónico, las generalizaciones de sentido común ${ }^{88}$ y las generalizaciones espurias, habida cuenta del alto estándar de prueba exigible en estos actos.

Asimismo, de acuerdo con Romeo Casabona, «no debería descartarse que con un desarrollo más perfeccionado y sofisticado de sistemas de inteligencia artificial éstos fueran capaces de predecir de forma objetiva -automatizada- el comportamiento criminal de un delincuente a la vista de su personalidad» (2018: 47), pero las expectativas a corto y medio plazo aún no son promisorias ${ }^{89}$.

87 Piénsese que un muestreo estadístico más amplio y adecuadamente validado, que recoja datos similares a los expuestos en cuanto a la prevalencia de fugas efectivas en delitos menores, descartaría el respaldo de la máxima de experiencia que dice que «la alta penalidad puede provocar que el investigado decida fugarse».

${ }^{88}$ Aunque este tipo de máximas de experiencia pueden servir como garantía en medidas cautelares de menos impacto, como el impedimento de salida del país o la restricción de ingreso a ciertas áreas, en donde el estándar de prueba es menor.

89 Cfr. Martínez Garay 2014: 52. 
Finalmente, algunos resultados provenientes también de la psicología experimental y relacionados con el análisis económico del derecho y que generan algunas predicciones sobre el comportamiento general de los seres humanos podrían tener una utilidad limitada, por ejemplo, con respecto a la aversión a la pérdida, la aversión al extremismo y la apariencia de justicia ${ }^{90}$, de donde podría derivarse, en cuanto a lo que aquí interesa, que una persona valore negativamente el mantenerse en la condición de prófugo, máxime cuando nos encontramos en sociedades omnidisciplinarias $^{91}$, lo que llevaría a la mayoría a no fugarse; o bien, el hecho de que la instrucción de un proceso penal contra un individuo implica, de forma automática, que si desaparece prueba inculpatoria el primer sospechoso sea el potencial beneficiado con el acto, lo que podría influir sobre la real ejecución de actos de obstaculización por parte del encartado.

\section{CONCLUSIONES}

A lo largo de este trabajo se han podido delinear algunos de los aspectos que repercuten en la toma de decisiones relativas a la procedencia o no de medidas cautelares de carácter personal en un proceso penal. Se ha enfatizado que existen al menos tres tipos de variables que afectan en la práctica la adecuada fundamentación de la premisa fáctica de este tipo de actos judiciales: los factores procesales positivos, los factores de resiliencia interna del juzgador y los factores estructurales de la pretensión.

En cuanto a los factores estructurales de la pretensión, se indicó que, mientras el fumus commissi delicti es una hipótesis probabilística de primer orden (sobre la posibilidad de que recaiga sentencia condenatoria), el periculum libertatis se configura, en la mayoría de las legislaciones, incluyendo la costarricense, como una hipótesis probabilística de segundo grado (debe corroborarse un hecho base y su secuela).

De acuerdo con la postura asumida, para mantener la finalidad cautelar de la medida y permitir un verdadero razonamiento probatorio es preciso enlazar la noción de peligro con la ejecución de acciones concretas, lo que significa entender el riego procesal como una hipótesis probabilística de primer orden, semejante al fumus commissi delicti.

Con relación a la inferencia probatoria en hechos prospectivos, partiendo del esquema argumentativo de Stephen Toulmin, se ha destacado la trascendencia de la garantía y su respaldo. No quedan claras las razones por las que, generalmente, en la disposición de medidas cautelares los decisores no explicitan esa parte del razonamiento, con lo que convierten la inferencia en un razonamiento entimemático, que sugiere además la posible automatización de la medida, es decir, que en la práctica

90 Las personas quieren actuar con justicia y ser vistas actuando con justicia (SUNSTEIN 2012: 60).

91 Parafraseando la referencia de Foucault con respecto a la prisión (2003: 238). 
se esté dando un ejercicio calificatorio o definitorio y no un razonamiento probatorio en sentido estricto.

Se ha excluido la posibilidad de utilizar como garantía presunciones iuris o definiciones, por lo que es preciso echar mano a máximas de experiencia. Estas máximas pueden corresponderse con leyes científicas de carácter universal, generalizaciones no universales con alto grado de probabilidad, generalizaciones de sentido común y generalizaciones espurias.

Para la aplicación de medidas cautelares con un alto impacto en la esfera de derechos y libertades de las personas (como la prisión preventiva o el monitoreo mediante mecanismos electrónicos de seguimiento ${ }^{92}$ ), que aparejan un alto umbral de prueba, requerirán que la garantía de la inferencia sea como mínimo una generalización no universal con alto grado de probabilidad, mientras que otro tipo de medidas menos invasivas podrían conformarse con generalizaciones de sentido común, habida cuenta del estándar probatorio más bajo que mantienen, pero excluyendo en cualquier caso las generalizaciones espurias.

Dentro de las herramientas que se utilizan para la predicción de conductas futuras, la psicología cognitiva, la estadística y la inteligencia artificial tienen como rasgo común que, en mayor o menor medida, parten de la base de estudios actuariales de grupo, que poco pueden decir sobre el comportamiento de un individuo concreto. Adicionalmente, estos modelos son permeables a sesgos o tienen el riesgo de ser sobreevaluados por parte del juzgador, cuando, al menos para el momento actual, la fiabilidad de sus resultados es muy limitada.

No obstante, se estima que estos mecanismos pueden tener mayor relevancia para la determinación de medidas cautelares de bajo impacto, siendo en principio insuficientes para la determinación de la prisión preventiva o el monitoreo electrónico. De cualquier manera, como propuesta de lege ferenda se estima imprescindible que legislativamente se incorporen en los diseńos procesales, estándares de prueba claros y diferenciados para las medidas cautelares rigurosas y para las medidas de baja injerencia ${ }^{93}$.

92 Debe hacerse hincapié en que el monitoreo electrónico representa una grave intrusión en la libertad e intimidad del usuario, de forma que, en la legislación procesal costarricense incluso se ha equiparado su utilización con la prisión preventiva, estableciendo el numeral 244 inciso j del CPP, como medida cautelar «La imposición de la medida de localización permanente con mecanismo electrónico. Para tal efecto, un día bajo localización permanente con dispositivo electrónico equivale a un día de prisión preventiva». Sobre este tema puede consultarse: MoRA 2017.

93 En la práctica judicial es usual que, ante el requerimiento de prisión preventiva por parte del Ministerio Público, la defensa técnica del encartado solicite se impongan medidas cautelares no limitativas de la libertad ambulatoria. El requerimiento de medidas coactivas por parte de la propia defensa, aunque posible con el actual diseño procesal costarricense, es, a mi juicio, una disfuncionalidad del sistema, que se potencia por la inexistencia de estándares diferenciados para la detención cautelar y para otro tipo de medidas. Si se definieran tales estándares, el Ministerio Público se vería obligado a gestionar, de 
Ahora bien, tanto los mecanismos de predicción analizados como los patrones estadísticos que reflejan el funcionamiento real de los sistemas de justicia, aunque poseen un alcance limitado como aval epistémico a nivel inferencial, si mantienen enorme trascendencia en cuanto al rendimiento de las instituciones y pueden ayudar a detectar disfuncionalidades -como se ha visto en el caso del uso desmedido de la prisión preventiva- y diseñar reformas normativas que mejoren la administración de justicia ${ }^{94}$.

Finalmente, considerando que el periculum libertatis debe entenderse como una hipótesis probabilística de primer orden, la capacidad predictiva de la conducta por medio de la psicología cognitiva aumenta sensiblemente su fiabilidad. Debe recordarse que todos los estudios de predictibilidad parten de una base retrospectiva, entendiéndose desde la psicología cognitiva que "[e]l futuro es un repetición del pasado, solo interesa la probabilidad que existe de que un hecho suceda en el futuro» (GARRIDO y González 2018: 11), por lo que la validez y solidez de una inferencia bajo esa estructura resulta diametralmente más fiable cuando ya se ha dado la concreción de algún acto de fuga u obstaculización de prueba.

\section{BIBLIOGRAFÍA}

Atienza, M., 2005: Las razones del derecho. Teorías de la argumentación jurídica, Universidad Nacional Autónoma de México.

Cerda lorca, J. y Valdivia Cabrera, G., 2020: Conceptos básicos de metodologías de investigación clínica y epidemiológica, Santiago: Ediciones Universidad Católica de Chile.

Chinchilla Calderón, R. y García Aguilar R., 2003: Disfuncionalidades en la aplicación de la prisión preventiva, San José: Investigaciones Jurídicas S.A.

Christie, N., 2004: Una sensata cantidad de delito, Buenos Aires: Editores del Puerto.

Dei VecChi, D., 2015a: «La peligrosidad judicial: Sobre la justificación de la premisa fáctica de la prisión preventiva en la decisión judicial y algunas críticas no tan frecuentes», La Ley Penal (115): $1-17$.

- 2015b. Peligrosidad judicial y encarcelamiento cautelar. una aproximación a la prisión preventiva desde la óptica de la justificación de decisiones judiciales, Buenos Aires: Ad-Hoc.

Echeburúa, E., Amor, P., Loinaz, I., y De Corral, P., 2010: «Escala de predicción del riesgo de violencia grave contra la pareja», Psicothema 22(4):1054-60.

Esbec, E., 2003: «Valoración de la peligrosidad criminal (riesgo-violencia) en Psicología forense. Aproximación conceptual e histórica». Psicopatología Clínica, Legal y Forense 3(2):45-64.

FernáNDez López, M., 2004: «Presunción de inocencia y carga de la prueba en el proceso penal», Universidad de Alicante.

Fernández Sepulveda, A., 1985: Derecho judicial y justicia constitucional: Una aproximación al tema, Madrid: Secretaría General Técnica. Ministerio de Justicia.

forma subsidiaria al requerimiento de prisión, otro tipo de cautelas, dado que, de rechazarse la solicitud principal, lo que procedería es la libertad del imputado, sin condicionamiento alguno.

94 «La buena capacidad para estimar el riesgo relativo de violencia o de reincidencia que tienen los instrumentos estructurados de valoración del riesgo puede constituir una información útil para la toma de determinadas decisiones en el ámbito judicial, especialmente aquellas que tengan que ver con la asignación de recursos escasos a un grupo de personas» (MARTínez GaraY 2016: 21). 
Ferrer Beltrán, J., 2019: Prueba y racionalidad de las decisiones judiciales, Hidalgo: CEJI.

Ferrua, P., 2018: «La prova nel processo penale», Revista Brasileira de Direito Processual Penal, 81-128. Foucault, M., 2003: Vigilar y castigar. Nacimiento de la prisión. 32a, Buenos Aires: Siglo Veintiuno Editores.

Freisler, R., 2017: Derecho penal de voluntad, Ciudad Autónoma de Buenos Aires: Ediar.

Garrido, V., y González, A., 2018: «La predicción de la delincuencia», Universitat Oberta de Catalunya.

González Lagier, D., 2013: Quaestio Facti. Ensayos sobre prueba, causalidad y acción, Primera Ed. México D.F.: Editorial Fontamara.

HAACK, S., 2014: Evidence matters: Science, proof, and truth in the law, New York: Cambridge University Press.

Hunter Ampuero, I., 2015: «Las dificultades probatorias en el proceso civil. Tratamiento doctrinal y jurisprudencial, críticas y una propuesta", Revista de Derecho Universidad Católica Del Norte, 209-57.

Informe, 2017: «Segundo Informe Estado de la Justicia», en Programa estado de la nación.

Informe, 2020: «Tercer Informe Estado de la Justicia», en Programa estado de la nación.

Larson, J., Mattu, S., Kirchner, L., y Angwin, J., 2016: «How we analyzed the COMPAS recidivism algorithm», ProPublica.

Llobet, J., 2017: Proceso penal comentado (Código procesal penal comentado), San José. Editorial Jurídica Continental.

- 2018: La Corte Interamericana de Derechos Humanos y las garantías penales, San José: Editorial Jurídica Continental.

Maier, J., 1996: Derecho procesal penal. Tomo I. Fundamentos. 2a, Buenos Aires: Editores del Puerto.

Mandracchia, J., y Morgan, R., 2011: «Predicting offenders" Criminogenic cognitions with status variables", Criminal Justice and Behavior.

MarTínez GaraY, L., 2014: «La incertidumbre de los pronósticos de peligrosidad: consecuencias para la dogmática de las medidas de seguridad», InDret 0(2):1-77.

— 2016: «Errores conceptuales en la estimación de riesgo de reincidencia», Revista Española de Investigación Criminológica 14(3):1-31.

- 2018: «Peligrosidad, algoritmos y due process: el caso State v Loomis», Revista de Derecho Penal y Criminología 20: 485-502.

Martínez Garay, L., y Montes Suay, F., 2018: «El uso de valoraciones del riesgo de violencia en derecho penal: algunas cautelas necesarias», InDret (2):1-46.

Méndez, C., 2015: Pensar la psicología, Madrid: Siglo XXI.

Miranda Estrampes, M., 1997: La mínima actividad probatoria en el proceso penal, Barcelona: J.M. Bosch.

Mora SÁnchez, J., 2015: Prisión preventiva y control de convencionalidad, San José: Editorial Juritexto.

- 2017: Mecanismos electrónicos de seguimiento ¿entre el panóptico y la prisión electrónica?, San José: Investigaciones Jurídicas S.A.

- 2018: «La prueba de hechos futuros», Revista Firma.

- 2019: «Dificultades probatorias en la prisión preventiva», pp. 205-48, en La prueba. Razonamiento probatorio y justificación de las decisiones judiciales y administrativas, San José: Investigaciones Jurídicas S.A.

Mora SÁnchez, J., et. al. 2019: La prueba. Razonamiento probatorio y justificación de las decisiones judiciales y administrativas, San José: Investigaciones Jurídicas S.A.

Muñoz Vicente, J.M., y López-Ossorio, J.J., 2016: «Valoración psicológica del riesgo de violencia: Alcance y limitaciones para su uso en el contexto forense», Anuario de Psicología Jurídica 26: $130-40$.

Navarro, J.J., y Pastor E., 2017: «Factores dinámicos en el comportamiento de delincuentes juveniles con perfil de ajuste social. Un estudio de reincidencia», Psychosocial Intervention 26:19-27.

Nieva Fenoll, J., 2010: La valoración de la prueba, Madrid: Marcial Pons.

— 2018: Inteligencia artificial y proceso judicial, Madrid: Marcial Pons. 
Nieva Fenoll, J., Ferrer Beltrán, J., y Giannini L., 2019: Contra la carga de la prueba, Madrid: Marcial Pons.

Pozo, J.I., 2006: Teorias cognitivas del aprendizaje, Madrid: Ediciones Morata.

Pueyo, A.A., y Echeburúa E., 2010: «Valoración del riesgo de violencia: Instrumentos disponibles e indicaciones de aplicación", Psicothema 22(3):403-9.

Pueyo, A.A., y Redondo S., 2007: «Predicción de la violencia: Entre la peligrosidad y la valoración del riesgo de violencia", Papeles Del Psicólogo 28(3):157-73.

Pujol Robinat, A., Mohíno Justes, S., y Gómez-Durán, E., 2014: «Valoración forense del riesgo de violencia", Medicina Clinica 142(2):16-23.

Romeo Casabona, C., 2018: «Riesgo, procedimientos actuariales basados en inteligencia artificial y medidas de seguridad", R.E.D.S. (13):39-55.

Schauer, F., 2013: Pensar como un abogado, Madrid: Marcial Pons.

Silva, D., Mercurio, E., y López F., 2008: Imputabilidad penal y neurociencias, Buenos Aires: Ad-Hoc.

Slobogin, C., 2019: "A defence of modern risk-based sentencing", en Predictive sentencing. Normative and empirical perspectives, Oxford: Hart.

Sunstein, C., 2012: «Análisis conductual del derecho", THEMIS-Revista de Derecho 0(62): 53-64.

Taruffo, M., 2010: Simplemente la verdad, Madrid: Marcial Pons.

Toulmin, S., 2007: Los usos de la argumentación, Barcelona: Ediciones Península.

Valenzuela, J., 2018: «Hacia un estándar de prueba cautelar en materia penal: Algunos apuntes para el caso de la prisión preventiva», Política Criminal. Vol. 13, N 26, 836-57.

Vega Monge, A., 2015: Populismo punitivo y medios de comunicación, San José: Editorial Jurídica Continental. 
